\title{
Route Type Determination Analysis
}

\author{
Brett Stone
}

September 2011

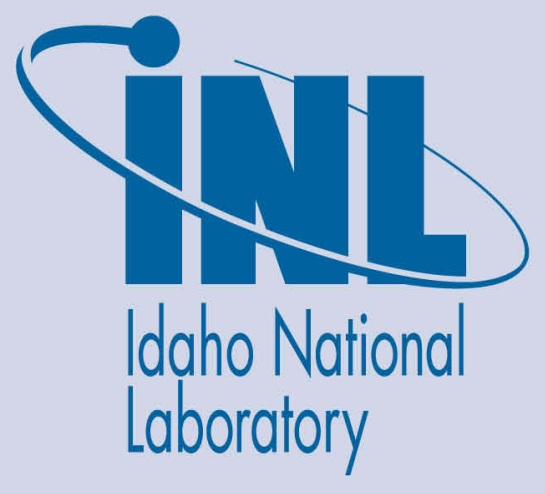

The INL is a U.S. Department of Energy National Laboratory operated by Battelle Energy Alliance 
INL/EXT-11-23204

\title{
Route Type Determination Analysis
}

\author{
Brett Stone
}

September 2011

\section{Idaho National Laboratory \\ Idaho Falls, Idaho 83415}

http://www.inl.gov

\author{
Prepared for the \\ U.S. Department of Energy \\ Assistant Secretary for Energy Efficiency and Renewable Energy \\ Under DOE Idaho Operations Office \\ Contract DE-AC07-05ID14517
}




\section{Route Type Determination Analysis}

\section{Brett Stone - Summer 2011 - INL AVTA}

According to the 2009 National Household Travel Survey ${ }^{1} 44.4$ percent of all miles travelled by Americans in 2009 (including airplanes, trains, boats, golf carts, subways, bikes, etc.) were travelled in cars. If vans, SUV's and pickup trucks are included, that level increases to 86 percent. We do a lot of travelling on the road in personal vehicles - it's important to be able to understand how we get there and how to rate the fuel economy of our trips. An essential part of this is knowing how to decide if a trip is a city or highway trip.

\section{Background}

In the early 1970's, not long after the Arab Oil Embargo prompted the price of gasoline to rise to previously un-heard of heights, the Society of Automotive Engineers (SAE) was tasked with developing a way to uniformly measure the fuel efficiency of all consumer vehicles ${ }^{2}$. To measure the efficiency of vehicles, the SAE first looked to the methods that had been privately developed by each of the "Big Three" car manufacturers; GM, Chrysler, and Ford.

Based on the manufacturer methods, the SAE task force recommended that "at least three distinct modes of vehicle operation should be evaluated to define fuel economy." Those three modes were:

1. City (Average speeds of $15-35 \mathrm{mph}$ with roughly 5 stops per mile)

2. Suburban (Average speeds of $24-42 \mathrm{mph}$ with roughly 1 stop per mile)

3. Interstate / Highway (Average speeds of $47-70 \mathrm{mph}$ with $0-0.1$ stops per mile)

However, this idea of three different classifications didn't stick. Not long after the SAE document was released, the EPA released a document ${ }^{3}$ in which it specified only two modes of driving; "City" and "Highway". These two categories have, for better or worse, dominated the development of fuel efficiency descriptions and ratings ever since.

\section{Methodology Comparison}

\section{INL Methodology}

INL has developed two different methods for determining route type. One is a General method, and the other is a method specially developed for U.S. Postal Service (USPS) vehicles.

\section{INL General}

\footnotetext{
${ }^{1}$ http://nhts.ornl.gov/tables09/FatCat.aspx

2 "The Development of the New SAE Motor Vehicle Fuel Economy Measurement Procedures, 1975,"

3 "Passenger Car Fuel Economy as Influenced by Trip Length" EPA, Austin \& Hellman, 1975,
} 
INL's General method for determining "City" or "Highway" classification works a little like a multi-level splitting filter. The first level of the filter designates that a trip with average speed greater than or equal to $37 \mathrm{mph}$ or equal to or less than $26 \mathrm{mph}$ is automatically classified as highway or city, respectively.

If, however, the average trip speed falls between those values, then the trip moves on to the next level of the filter: average number of stops per mile (stops/mi.). A trip that averages more than 2.5 stops/mi. driven is labeled a city trip. If less than one stops/mi. is averaged, the trip is labeled a highway trip.

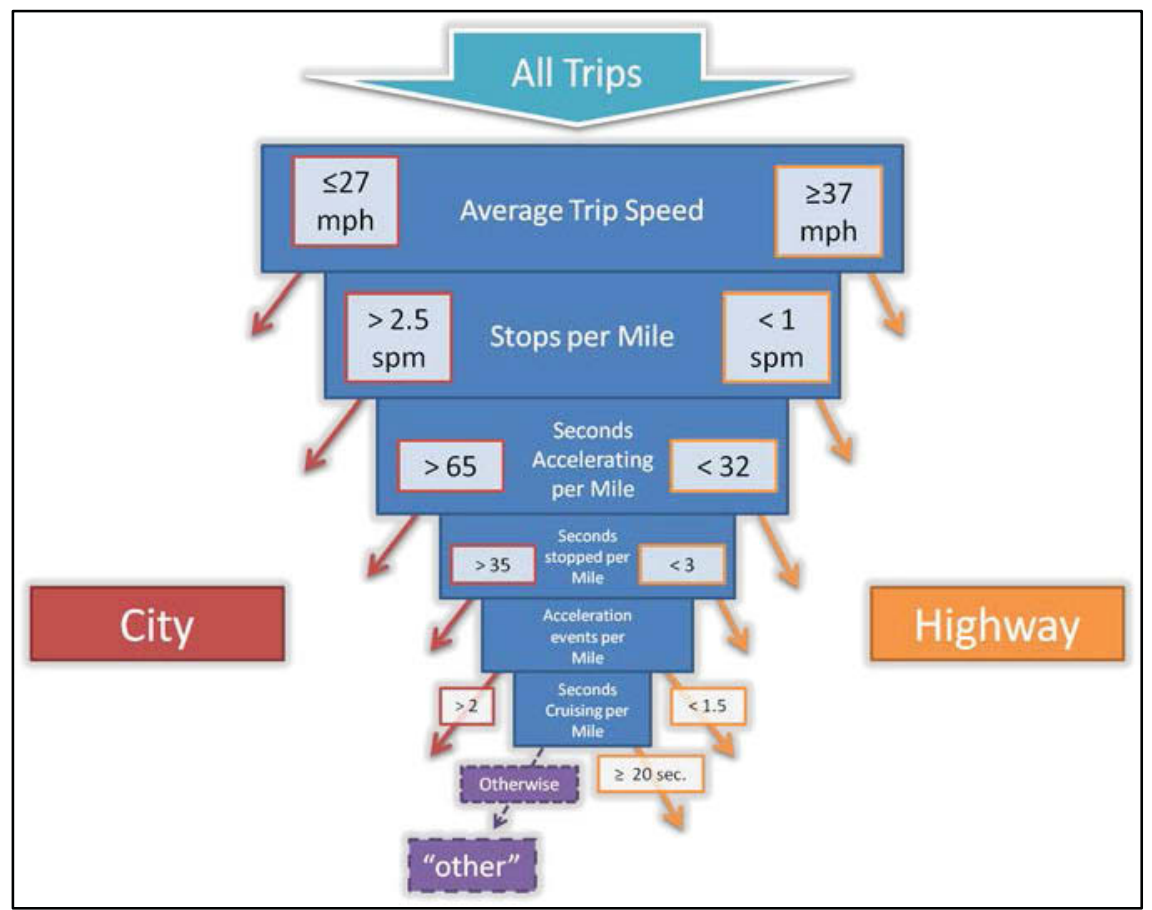

Figure 1: Visual schematic of the INL General route type determination methodology. Note that by the third level well over 90 percent 90 percent of trips have been classified in most cases.

But, if the trip has between 1 and 2.5 stops/mi., the third level of the filter is used; seconds accelerating per mile. By the third level, in most cases, well over 90 percent of trips have been classified as either city or highway. However the filter contains several more levels to determine which category a trip belongs to. The INL's method is further detailed in Figure 1.

\section{INL USPS}

The INL's method for determining highway or city trip type for USPS delivery vehicles bears only some similarity to the more complex General method explained above. Since 67 percent of USPS trips are less than two miles long and average more than 30 stops per mile, a simpler approach can be used by adding an additional trip type: "Stop and Go". These trips are defined as having more than 5 stops per mile.

Meanwhile, city trips are classified as having less than 5 stops per mile and average trip speeds less than $37 \mathrm{mph}$, while highway trips (which only account for less than 1 percent of all trips or 4 percent of VMT) also have less than 5 stops per mile and average speeds equal to or above $37 \mathrm{mph}$. See Table 4 (appendix) for more information on the USPS fleet and route types. 


\section{Society of Automotive Engineers J2841 Methodologies}

SAE offers four different methods ${ }^{4}$ for determining route-type. All are based on the long standing precedent of a commonly assumed split of 55 percent city miles / 45 percent highway miles. The four methods are:

1. Basic (refer to Figure 2)

- Sets a divider at $42 \mathrm{mph}$ for average trip speed. Trips at and above this speed are considered highway driving.

- Uses data from the Department of Transportation's National Household Travel Survey (NHTS) and the common assumption that 55 percent of Vehicle Miles Traveled (VMT) is traveled in citylike driving conditions to arrive at the 42 mph divider.

- Agrees with the INL General method on 78 percent of trips and 81 percent of VMT using data from all trips from the Green IT Alliance Hymotion Prius vehicle. (Other data sets show varying levels of agreement).

- Benefits include being quick and easy to

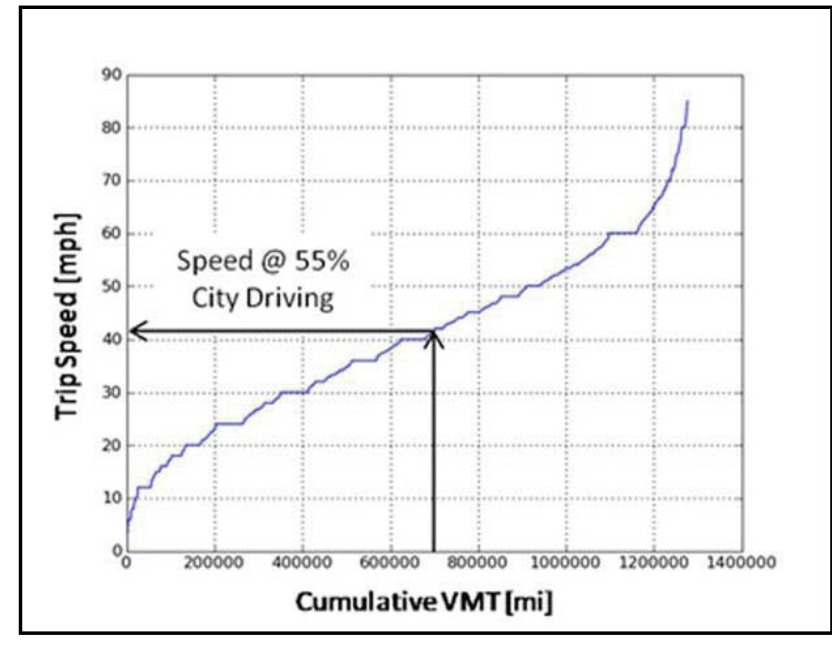

Figure 2: Graph of Trip Speed vs. Cumulative Vehicle Miles Travelled (VMT) from the NHTS. By identifying the point where 55 percent of VMT has been travelled on the curve and the average trip speed that correlates to, $\mathbf{4 2} \mathrm{mph}$ was identified as the "dividing line" for average trip speed. (Image courtesy of SAE J2841) use. The only parameter needed to decide route type is average speed.

- Disadvantages include being overly-simplistic in many cases. Trips that have high average speeds because of high rates of acceleration between frequent stops can still be classified as "highway" driving even though they have effects on the vehicle that are similar to or worse than city driving.

2. " $X "$ " fit (refer to figure 3)

- Sets two "cutoff" speeds. Below $25 \mathrm{mph}$ is automatically city and above $60 \mathrm{mph}$ is automatically highway

- Between those two speeds, a trip is "weighted" as a certain percent highway (or city) based on its average trip speed. If the weight of a trip in the mixed region is higher than 50 percent the trip is classified as either city or highway. For example, if the difference between the average speed of a given trip and the cutoff speed for city is less than half the difference between the city cutoff and the highway threshold (a weighting of more than 50 percent City), that trip would be classified as a city trip, and vice-versa for the opposite situation. See figure 3 for more.

- Agrees with the INL General method on 77 percent of trips and on 80 percent of VMT using data from the Green IT Alliance Hymotion Prius vehicle.

\footnotetext{
${ }^{4}$ See SAE document J2841
} 
- Benefits include not being forced to call trips in the mixed region 100 percent city or highway, but having a little bit of room to explain unusual trips.

- Disadvantages include not being able to definitively identify a large portion of trips.

0 Interestingly, the average trip speed at the midpoint between 100 percent city and 100 percent highway is $42.5 \mathrm{mph}$ (using the same sample of trips as before), nearly the same as the cutoff for the "Basic" method discussed earlier. For more on the " $X$ " fit method,

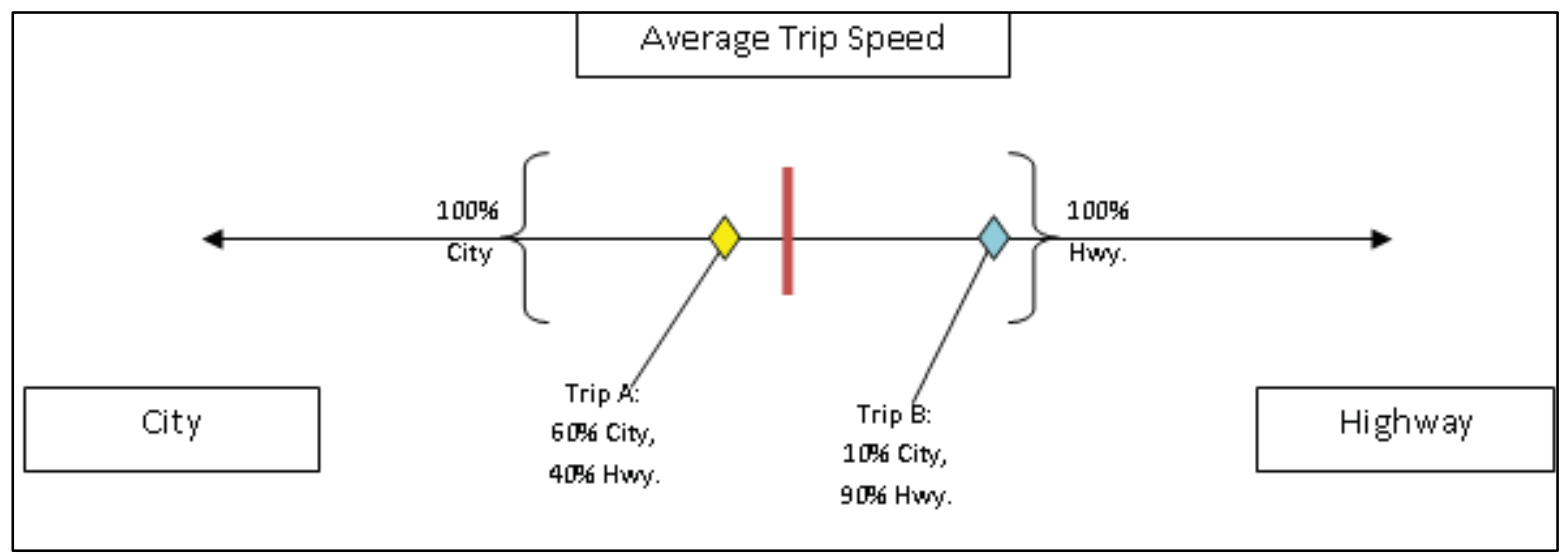

Figure 3: Continuum of average trip speed with divisions corresponding to city, mixed, and highway trip route types for the " $X$ " fit route type determination method. Note that, from the standpoint of determining if a trip was a city trip or a highway trip, the method works essentially the same as having a single cutoff speed. However, if used instead as a tool for estimating probability of trip type instead of being the final, determining factor, an observer can give the likelihood that a given trip will be classified as either city or highway. So, the probability that "Trip A" would be a city trip is about 60 percent, while a trip made at the same average speed as "Trip B" would have a 90 percent likelihood of being a highway trip.

including graphs, see appendix.

- Again, the method is based on the assumption of a 55/45 split, and thus the cutoff speeds involved will differ slightly for each sample. Standard cutoff speeds could be determined from one large sample.

3. "Common Ground"

- Also uses three sections to divide the average speed data: City, Shared, and Highway. The sections are divided at speed intervals similar to the " $X$ " fit method.

- The Shared section trips are included by both city and highway when calculating fuel economy. See Figure 4.

- Produces a proportion of city and highway trips that is similar to INL's General method (about 92 percent similar), however, it is impossible in many cases to exactly indentify which trips the two methods are agreeing on, since the Common Ground method counts many trips twice, once as a city and again as a highway trip. For this reason, the Common Ground method may be useful for very high level statistical analysis such as estimating percent highway travel from a given data set, but is not helpful for more specific needs. 


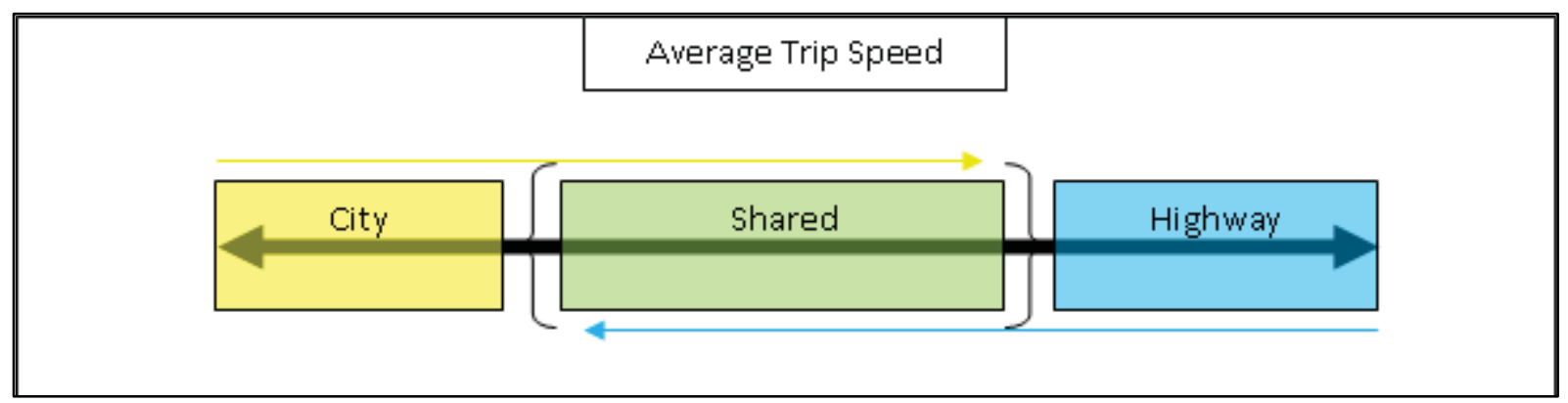

Figure 4: Continuum of average trip speed with divisions corresponding to city, shared, and highway trip route types for the Common Ground route type determination method. For calculating city fuel economy, trips from the city and shared category are considered, and for highway fuel economy, trips from the highway and shared sections are included. The idea is that trips in the shared section are equally as likely to be city or highway trips, so they are included in both calculations.

\section{Speed \& Stops}

- The most complex of the $\mathbf{J} 2841$ methods: Considers either an entire day's driving or a single trip for classification as city or highway.

- In the case of considering an entire day, average speed for the whole day's driving is compared to the number of trips taken during the day. This ratio and a minimum speed determine whether that day is classified as city or highway.

- A similar method is used when considering trips (instead of days) and stops during a trip (instead of trips). This is the version of the method analyzed for this report.

- The ratio and minimum speed are adjusted so that the mix of driving is still distributed according to a 55 percent city / 45 percent highway mix.

- Accounts for more factors than the other $\mathrm{J} 2841$ methods. For example, a trip may have high average speed and would be classified by the other methods as a city trip, despite also having a high number of stops (a factor not directly considered by the other methods). The "Speed \& Stops" method would classify this trip more appropriately as a city trip.

- As well, even though there may not be many stops during a trip, a trip still has to meet a minimum average speed to be classified as a highway trip.

- Agrees with the INL method on 76 percent of trips, but only 54 percent of VMT using Green IT Alliance Hymotion Prius vehicle data. See figure 20 (appendix) for more on this disparity.

\section{Micro-Trip Analysis}

Another approach to route type determination was developed called Micro-Trip Analysis. It breaks each trip up into smaller micro-trips (MT) that are each analyzed and determined to ; be either city or highway. The beginning and end points of a MT are determined by the points where the vehicle's velocity rises (to begin a MT) or falls (to end a MT) past a certain velocity threshold. In this analysis, 5 
mph was used (the same threshold used to define "stops" by INL General). Then, based on either the time or distance covered by each MT, the entire trip can be classified as either city or highway, or, similar to the SAE " $X$ " fit method, the trip can be given a percent city/highway classification.

The method for evaluating each micro-trip could be any of the methods described so far in this document. There may also be other methods that could be more specifically developed for MT analysis. In this case, an adapted version of the INL General method was used. At the beginning of the development of the MT Analyzer (MTA), a trip, drive301651 from the Green IT Alliance Hymotion Prius vehicle, was broken down into three MT's and each of these was analyzed using the INL General method, beginning with average speed.

Once one of the five filter levels identified the MT to be either city or highway, the analysis of that MT was considered finished and the MT was weighted. For comparison, weighting according to both time and distance were calculated.

Level four of the INL General method could not be used and was omitted from the analysis because of the intrinsic nature of MT's. Level four is the number of seconds stopped per mile of a trip, but since MT's are defined as beginning with an acceleration event and ending when the speed drops below a certain threshold ( $5 \mathrm{mph}$ in this case), it's impossible for a MT to have any seconds stopped per mile.

How to weight each MT once its type is determined is an interesting question. Two main options for weighting exist: 1) time, and 2) distance. In the example trip, both the time and distance weighted calculations returned the same route type (city) for the entire trip. This was also the same classification that was given to the trip by the INL General method (applied to the whole trip) and the SAE Basic method. However, the two weightings used in the MT analysis were significantly different. A time-based weighting tended 30 percent more towards a city route type than a distance-based weighting.

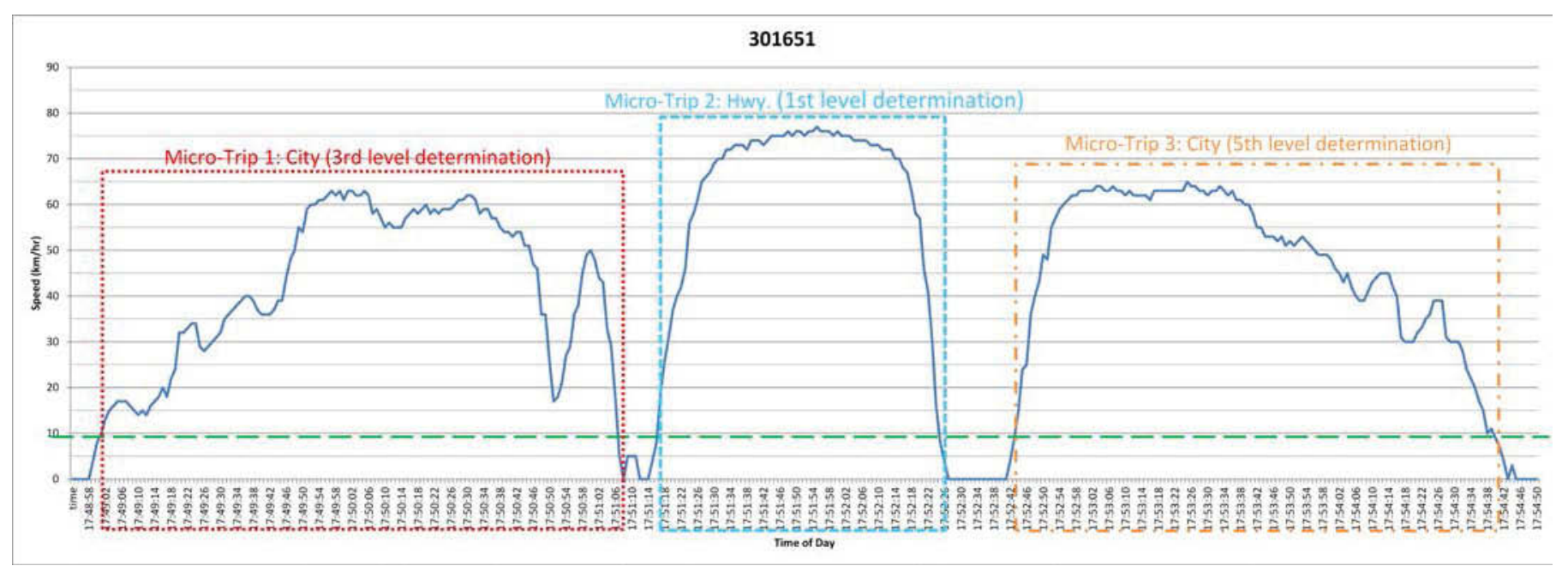

Figure 5: Speed vs. Time graph of example trip investigated using micro-trip analysis. As can be observed, three sections form the microtrips, indicated by colored squares. The green line indicates the threshold speed for beginning and ending micro-trips. MicroTrip Analysis allows for every major acceleration event to be considered in the determination of whether a trip is a city trip or a highway trip. In this case INL's General method for route type determination was adapted for MT analysis. However, any variety of methodologies could be used. Note: speeds in $\mathrm{km} / \mathrm{hr}$. 
The cause behind this difference is apparent when considering how small the distance travelled, if any, is when vehicle speed is somewhere below $5 \mathrm{mph}$. On the other hand, the passage of time does not diminish when vehicle speed drops below a certain point. This difference in weight determination could mean the difference in whether many trips with less certain route types are determined to be city or highway trips.

What to do with the time and distance not covered by the micro-trips (when speed is less than $5 \mathrm{mph}$ ) led to the addition of another interesting adaptation. Time or distance during the trip not covered by one of the micro-trips was, of course, covered during time-periods when speed was less than $5 \mathrm{mph}$, and so would pertain to the city weighting of the overall route type determination calculation. As could be expected, adding these portions made much less of a difference in the weighting based on mileage than they did in the weighting based on time, since, due to the low speeds in the areas concerned, the distance covered in these periods was significantly less than other portions.

A MatLab program was written to automate the process of MT analysis. This "MT Analyzer" or MTA, reduces the time needed to analyze large numbers of trips exponentially compared to an Excel based analysis. A small number of changes were made to the MatLab version of the MTA. One change was to simply omit the miles not included in one of the MT's from distance weighted analysis, since the distance travelled when speed was less than $5 \mathrm{mph}$ is insignificant compared to the total distance travelled.

Meanwhile, the time not included in any of the MT's was considered in the time-based weighting since the accumulation of time, unlike distance, is not diminished as speed decreases. This time is called "U.A. time" for, "Unaccounted for Time" and is one of the distinguishing features that sets the MTA apart from other, somewhat similar approaches ${ }^{5}$ to route type determination.

\section{Hymotion Prius Fleet Analysis}

\section{Comparative Splits}

The SAE Basic method sets a cutoff speed for highway and city trips at $42 \mathrm{mph}$. This speed is based on a calculation made using data from a national survey, and so using the same calculation methods with a different set of data should result in a cutoff speed that is at least slightly different. How different the resultant speed is when determined using another large data set gives insight into how representative the SAE Basic method is.

By applying a 55 / 45 percent VMT city / highway split to the data from the entire Hymotion Prius fleet (more than 2.5 million cumulative VMT) a comparison between cutoff speeds was made. The Hymotion Prius data, represented graphically in Figure 6, resulted in a cutoff speed of roughly $45 \mathrm{mph}$, as opposed to the $42 \mathrm{mph}$ in the SAE J2841 method. This difference in cutoff speeds is only 6 percent and would

\footnotetext{
5 "From driving cycle analysis to understanding battery performance in real-life electric hybrid vehicle operation", by Bor Yann Liaw and Matthieu Dubarry, Journal of Power Sources 174 (2007) 76-88 
seem to imply a high degree of applicability for the method across data sets. In other words, the $42 \mathrm{mph}$ cutoff speed from the SAE Basic method seems reasonable.

When re-vamping its rules and labels for fuel-efficiency recently ${ }^{6}$, the U.S. Environmental Protection Agency (EPA) also re-examined its method for splitting the city and highway proportions of its technique. It recommended changing to a $43 / 57$ split, believing that this ratio more accurately represents the types of miles covered by today's drivers. However, this idea was rejected after negative public feedback focused on the non-intuitive nature of the split and the realization that the 55 / 45 split was still used in laws such as the 'Gas Guzzler Tax'. The EPA feared that confusion would be created. Even though the 43 / 57 split might be more accurate, if that ratio was used for fuel efficiency ratings for vehicle-window labels, while for tax purposes a different proportion was used, the inconsistency among ratings could prove frustrating for consumers and manufacturers alike.

Still, by plotting the 43 / 57 split on the graph of the Hymotion Prius data an interesting result can be seen. The resulting speed for the cutoff is $37 \mathrm{mph}$, exactly the speed required by the INL General method for automatic highway classification in the first filter level.

\section{Micro-Trip Splits}

A sample of more than 18,000 trips from the V2Green database (mostly Hymotion Prius and Escape vehicles) was taken to demonstrate the ability to quantify the proportions of city/highway trips using large sets of data and the MT Analysis method. The trips, whose average trip speeds ranged from 29 to $34 \mathrm{mph}$, were near the center of the section of "indeterminate" average speeds from the first level filter of the INL General method. The resulting proportions were roughly similar to what might be expected: the INL General method classified the sample with a split of about 35/65 percent city/highway.

Information on what percentage of each individual trip was city or highway like was also generated using MTA. Weightings according to both percentage of time and percentage of distance travelled were

\footnotetext{
6 "Response to Comments: Fuel Economy Labeling of Motor Vehicles, Office of Transportation and Air Quality, EPA420-R-06-016, December 2006
}

Route Types Explained BRS, 2011 
used for each trip. For example, some of the overall information generated for Drive 100910 is shown in Table 1.

Table 1 shows some of the information contained in the "Trip Info Table", one of two types of tables automatically generated by MTA for each set of trips processed. Here, data is shown for just one trip. Note: "U.A. Time" stands for "Unaccounted for Time", or trip time not included in one of the micro-trips. This time is either time idling or time where vehicle speed was less than five $\mathrm{mph}$ and is weighted toward city classification for the overall trip.

\begin{tabular}{|c|c|c|c|c|}
\hline \multicolumn{5}{|c|}{ Table 1: Drive 100910 (from “Trip Info Table" overall statistics) } \\
\hline $\begin{array}{c}\text { INL General } \\
\text { Route Type } \\
\text { Classification }\end{array}$ & $\begin{array}{c}\text { Total Trip Distance } \\
\text { (miles) }\end{array}$ & Total Time (hours) & Avg. Speed (mph) & Stops / Mile \\
\hline Highway & 16.5 & 0.56 & 29.14 & 0.73 \\
\hline $\begin{array}{c}\text { Percent Miles } \\
\text { Travelled City }\end{array}$ & $\begin{array}{c}\text { Percent Miles } \\
\text { Travelled Hwy. }\end{array}$ & Percent Time City & Percent Time Hwy. & "U.A." Time (sec) \\
\hline 35.33 & 64.66 & 58.58 & 41.42 & 147.94 \\
\hline
\end{tabular}

Table 2 shows a breakdown of the same trip into its individual micro-trips. This table is also automatically generated by MTA. As can be seen, the trip was divided into 12 distinct micro-trips and each micro-trip was assigned a route type based on information generated by the MTA. For context, a speed trace and other graphic data on Drive 100910 can be found in the appendix, figures 23 and 24.

Table 2 shows an example of a "Hill Table," generated automatically for each trip. Here, each "hill," or micro-trip from the trip Drive 100910 is shown with the results of each micro-trip's analysis. This trip contained 12 micro-trips, but it is not uncommon for a trip to have as many as $\mathbf{2 0}$ micro-trips. The last column indicates on which level of the adapted INL General filter the micro-trip's route type was determined. Most micro-trips are determined on the first or second level.

\begin{tabular}{|c|c|c|c|c|c|c|}
\hline \multicolumn{7}{|c|}{ Table 2: Drive 100910 (from “Hill Table," individual trip statistics) } \\
\hline $\begin{array}{c}\text { Micro-Trip } \\
\#\end{array}$ & $\begin{array}{c}\text { Route } \\
\text { Type }\end{array}$ & $\begin{array}{c}\text { Avg. Speed } \\
(\mathrm{mph})\end{array}$ & $\begin{array}{c}\text { Trip Length } \\
\text { (miles) }\end{array}$ & $\begin{array}{c}\text { Stops / } \\
\text { Mile }\end{array}$ & $\begin{array}{c}\text { Trip Time } \\
(\mathrm{sec})\end{array}$ & $\begin{array}{c}\text { Determination } \\
\text { Level }\end{array}$ \\
\hline 1 & City & 15.02 & 0.09 & 11.61 & 20.01 & 1 \\
\hline 2 & City & 17.14 & 0.77 & 1.30 & 161.06 & 1 \\
\hline 3 & City & 15.00 & 0.16 & 6.37 & 37.01 & 1 \\
\hline 4 & City & 16.04 & 0.26 & 3.83 & 58.02 & 1 \\
\hline 5 & City & 14.19 & 0.08 & 12.39 & 20.00 & 1 \\
\hline 6 & City & 23.29 & 3.85 & 0.26 & 594.20 & 1 \\
\hline 7 & City & 14.90 & 0.10 & 10.24 & 23.01 & 1 \\
\hline 8 & Hwy & 49.93 & 8.82 & 0.11 & 635.20 & 1 \\
\hline 9 & Hwy & 33.16 & 1.80 & 0.55 & 195.06 & 2 \\
\hline 10 & City & 18.34 & 0.39 & 2.59 & 75.03 & 1 \\
\hline 11 & City & 13.33 & 0.06 & 16.37 & 16.01 & 1 \\
\hline 12 & City & 9.13 & 0.06 & 17.89 & 22.00 & 1 \\
\hline
\end{tabular}




\section{Comparison: INL General and MTA}

As can be seen in Table 1, the INL General method classified drive 100910 as a highway trip, and 65 percent of the trip was classified as highway (weighting by distance travelled) by the MTA. But, if considering the other half of the MTA's analysis, weighting by time covered during travel, only 41 percent of the trip's time was in highway travel. Thus, the MicroTrip Analyzer (MTA) disagreed with the INL General method's classification of route type in one case for this trip. Drive 100910 was not an isolated case either.

"Disagreement" here is defined as the MTA identifying less than 50 percent of a trip as the same route type as the INL General method claims it to be. This can be applied to either time or distance weighting. For example, in the case of Drive 100910, which INL General identified as a highway trip, MTA "disagrees" under the percent time highway weighting since only 41 percent of the trip's travel time was given that classification. Meanwhile, considering distance weighting, MTA "agrees" with INL General since more than 50 percent of the trip miles were traveled in a highway-like driving pattern.

From the entire sample of more than 18,000 trips, INL General and MTA agreed more often than not; on about 58 percent of the trips in terms of both distance and time. The two methods agree on about 76 percent of trips when at least one of the two MTA weighting schemes agreed with INL General's classification. If exclusively considering either distance weighting or time weighting, the agreement is 65 percent for distance weighting and 69 percent for time weighting.

To check to see if the sample had the properties of a "normal" population and if the methods used for finding these statistics was correct, a Basic rule of statistics was used. For non-mutually exclusive events ${ }^{7}$ :

$$
P(A \text { or } B)=P(A)+P(B)-P(A \text { and } B)
$$

where in $P(A)$ is the probability of distance agreement (65 percent) and $P(B)$ is the probability of time agreement (69 percent) and $P(A$ and $B)$ is the percentage of trips that are agreed on by both time and distance weightings (58 percent). Entering these values into the above formula should provide the same value as was obtained in the agreement analysis for having at least one of the weighting methods agree with the INL General classification (76 percent). It can be seen that this is the case:

$$
P(A \text { or } B)=0.65+0.69-0.58=0.76
$$

\section{Characterizing Route Type Method Disagreement}

A particularly interesting subset of the samples is the portion where the two methods disagree in both the distance and time weightings. These "dual" disagreements are a complex group because of the fact that they vary so widely in how much each trip disagrees with the INL General method. Remembering that MTA classifies each trip with a certain percentage of highway and city-like mileage and time, each trip can agree with the INL General method to varying levels.

${ }^{7}$ http://people.richland.edu/james/lecture/m170/ch05-rul.html 
A trip might be classified by MTA as 49 percent highway by distance and 46 percent highway by time, while INL says the entire trip is Highway. Technically, the trip classifications are in "dual" disagreement, although the difference between MTA calling it the same thing as INL General is only very small. See figure 24 (appendix).

However, some other trips may be classified as 80 or 90 percent highway or city by both time and distance MTA, but be called the opposite by INL General. Thus, not only do MTA and INL General disagree on these trips, they disagree strongly. These trips tend to be very, very rare. Only about two percent of the trips from the sample, considering both distance and time weighting, disagree at levels of more than 90 percent. On the other hand, in the distance weighting category, a significant number of trips agree nearly completely with the INL General method. About 14 percent of all trips measured by the distance weighted method agreed 100 percent with the INL General method's classification.

While it is not uncommon for a trip to be composed of more than $20 \mathrm{MT}$ 's, roughly half of the trips that had 100 percent (distance weighted) agreement with the INL General method only had one stop for the whole trip. Trips with only two stops made up another quarter of the "100 per-centers". These observations and random sampling of actual speed traces of trips from this group support the theory that many of these trips have only one or two MT's. In this scenario, MTA walks something of a tightrope when classifying the overall trip, since one small difference in a measuring method in one MT could cause the entire trip to be classified the same or opposite INL General's classification. The fact that in these situations, a much larger number of trips were classified 100 percent the same as INL General rather than 100 percent opposite is a testament to the MTA concept, since it would be expected to return similar results based on the fact that its filtering capability is adapted from INL General.

\section{Considering INL General Adjustment}

In order to decide if, based on information from MTA, the INL General method should be adjusted, it's important to know how much the two methods agree. Earlier, based on a sample of roughly 18,000 trips, ranging from 29 to $34 \mathrm{mph}$ average trip speed, an estimate of 76 percent "at least partial" agreement was made. While the number of trips in the sample may be relatively large, this estimate by itself does not tell the whole story.

As more samples were considered, a clearer picture of agreement between the methods, as well as the factors affecting agreement emerged. Two other samples were analyzed in the same manner as the first. The first follow-up sample consisted of nearly 20,000 trips, ranging from 25 to $43 \mathrm{mph}$ average trip speed. The second follow up sample was made up of almost 4,500 trips and covered all ranges of average trip speeds and these trips all belonged to one vehicle, the Green IT Alliance vehicle. 


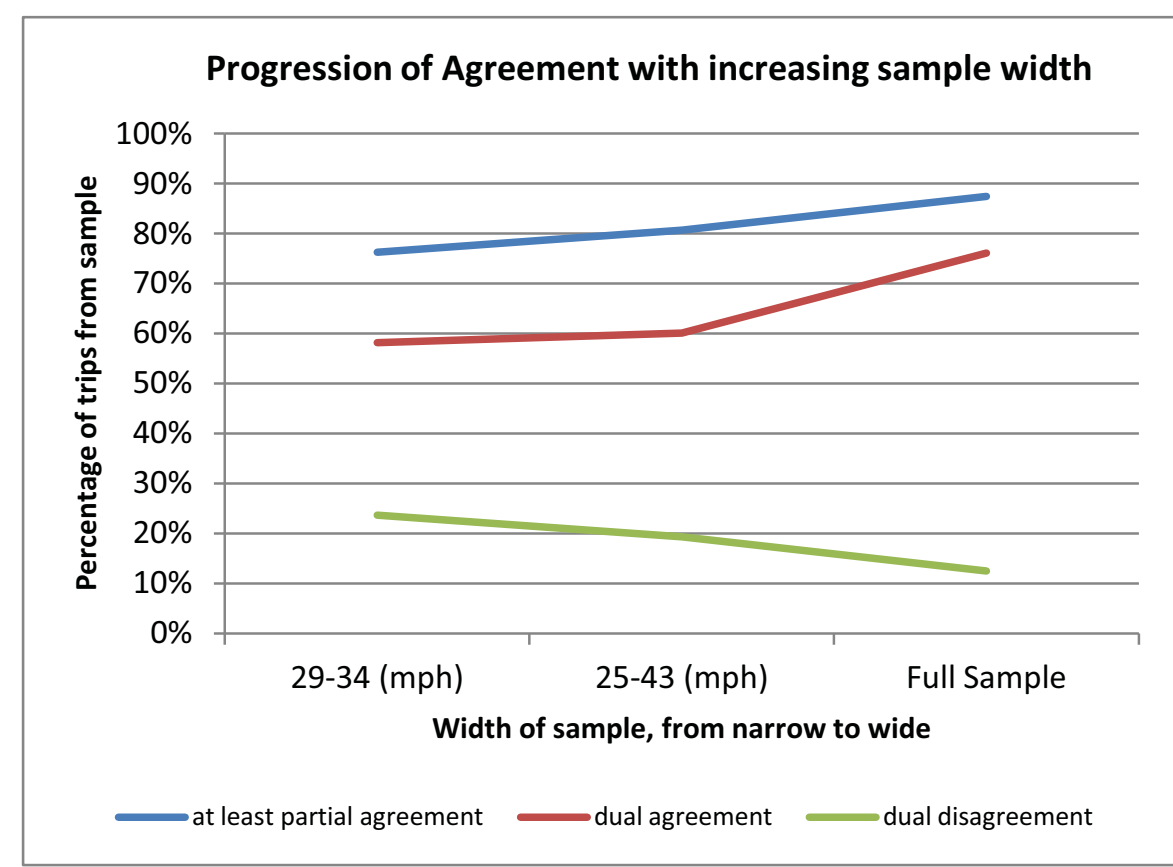

Figure 7 shows how as sample width increases, from a narrow selection of average trip speeds (mph) to considering all trips, the level of agreement between MTA and INL General increases. This would suggest that INL General and MTA have, in reality, a high overall level of agreement, and that INL General does not merit any drastic adjustment.
INL/EXT-11-23204

The three samples, together with the results of their agreement analysis, provide very valuable insight when viewed in order from narrowest spread of average trip speeds to widest, as seen in figure 7.

It becomes apparent that as more and more types of trips are considered, the two methods agree more and more completely. The histograms showing the distribution of agreement levels for each sample and other data also support this conclusion and can be seen in the appendix (figure 24 and table 5).

This combination of data does not support changing the INL General methodology. Instead, the trend shown in the data suggests that, overall, INL General and MTA have a very high level of agreement. If data from only one or two of the samples had suggested a high level of congruency between the methods, the conclusion of high agreement that improves as sample width increases would have been subject to at least some healthy skepticism. However, with three different samples that uniformly support the idea, it seems very likely that such a conclusion is sound.

\section{Understanding the last 12 percent}

The 12 percent of trips that, in the case of the Green IT Alliance vehicle, INL disagrees with MTA on both time and distance weighting classifications were analyzed to attempt to understand why the methods disagreed on their classification. Several trends were noted during this analysis. Dually disagreed on trips were likely: slower and shorter than the average Green IT Alliance trip, had fewer stops and fewer stops/mi., and were often about 7 miles, or 20 minutes long.

As can probably be easily noticed by this last fact, the average trip speed of these trips was usually ( 87 percent of dually disagreed on trips) below the $26 \mathrm{mph}$ limit used by INL General to automatically designate city trips. So, in most of these cases, INL General could immediately classify these trips as city trips without having to go past the first level of its filter. Trips classified as city by INL made up 98 percent of the dually disagreed on trips.

Various possible explanations for the disagreed upon trips include the following: the fact that MTA's filter, while based on the INL General method, is not the same. MTA omits the fourth level filter (number of seconds stopped per mile) entirely. However, since the great majority of MT's are classified by the first or second level of filtering, it's likely that this difference had only a small impact on the 
classification of trips. The nature of MT's may also make some intrinsic and unintended changes. For example, in the INL General filter, level two is stops/mi.. MTA obviously can't measures the number of stops per mile of a MT in a traditional sense because MT's have only one stop each by their nature. So, instead, an "equivalent" measurement is made that simply looks at the distance of each MT and uses that as the denominator in a "stops per mile" fraction (the number of stops will always be one for a MT, so the distance is the only thing that changes. Considering the overall trip, the stops/mi. rating remains virtually the same; however, the classification of individual MT's can be affected, which can, in turn affect the overall trip's classification.

Another possible reason may be related to the mathematics principle that the average of averages is not necessarily the same as the average of a population. While INL General analyzes entire trips based on average trip statistics, MTA weights each MT that makes up a trip according to its time and distance. This results in MTA's overall trip statistics appearing different in many cases from the INL General statistics for the same trip. For example, "MavgSpeed," or the trip average speed according to the MT's,

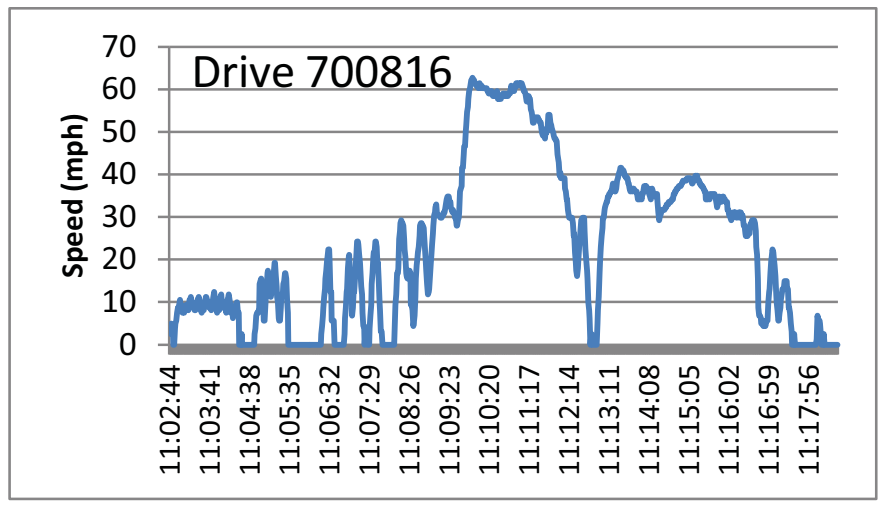

Figure 8: Drive 700816 provides a good example of the difficult to classify 12 percent of trips from the Green IT Alliance vehicle that were dually disagreed on by MTA and INL General. This trip had an overall average speed of only $23 \mathrm{mph}$ and $11 \mathrm{MT}$ 's, two of which were highway MT's. One of those highway MT's was classified on level two of the filter (stops per mile) since its average speed was only $33 \mathrm{mph}$. Still, these two MT's covered more than 85 percent of the entire trip's mileage and 65 percent of its time, and so, according to weight, the trip was classified as highway by MTA in both time and distance categories. is consistently higher than the "AvgSpeed" calculated by INL General because MavgSpeed cuts out all the time in between MT's. However, "MavgSpeed" was still less than $26 \mathrm{mph}$ in 15 percent of trips being considered.

When investigating speed traces from some trips that displayed characteristics of a "typical" dually disagreed upon trip (such as drive 700816), it was found that out of several MT's, only one or two would be classified as highway, and that often, at least one of the highway micro-trips had a low enough average speed to not be classified as highway until after the first level of filtering.

These trips appear to have still managed to be classified as highway trips by MTA mostly because of the significance of weighting. Weighting micro-trips based on time or distance seems to Generally increase the likelihood of classifying a trip as highway instead of city. The longer (either time or distance) a micro-trip is, the more likely it is to be a highway MT. A single, contiguous trip that continues without stopping for long periods of time or long distances is much more likely to have higher average speeds, fewer stops per mile, and tend toward highway classification on every filter level. Since MT's like this are also longer, they also carry more weight in the overall trip type calculation. In this way, highway trips count for more when it comes to MT analysis.

Including U.A. time (time spent travelling at less than five $\mathrm{mph}$ ) in the time weighting category made at least a small difference in bringing INL General and MTA closer together: about one fifth of the dually 
disagreed upon trips had very weak disagreement according to MTA time weighting ("weak" meaning less than 10 percent disagreement) and over 60 percent of the trips being considered were disagreed on at a level of between 10 and 50 percent. So, according to time weighting, the disagreements between the two methods were quite minor and a small change in the trip could have easily changed its classification. Meanwhile, distance weighting produced almost the opposite result with Generally strong disagreement. One third of the disagreed upon trips were above 90 percent disagreement, and over one half of the disagreed upon trips were between 50 and 90 percent disagreement.

Another anomaly concerning U.A. time is that while dually disagreed upon trips have more U.A. time than the average trip, they also have significantly less idle time than the average trip. Normally, idling time and U.A. time have at least a loose positive correlattion, since U.A. time consists of time accumulated when vehicle speed is below $5 \mathrm{mph}$, and idling time is time spent with vehicle speed at 0 $\mathrm{mph}$. The implication of this data point would seem to be that these dually disagreed upon trips are spending a disproportionately large amount of trip time at speeds below $5 \mathrm{mph}$, but not completely stopped. This a-typical behavior might suggest that this specific vehicle may have some unique role or responsibility that requires it to drive these trips that are being dually disagreed on. In any case, it seems out of the norm, and could indicate that these disagreed upon trips are themselves the anomaly and may not be a significant point of concern.

\section{Comparing J2841 and MTA}

MTA was also compared to the SAE Basic method using a similar comparison method to that used for MTA and INL General.

SAE Basic disagreed much more often than it agreed with MTA on the classification of trips in the sample of nearly 20,000 trips shown in figure 10 . Investigating trips in the 85 percent disagreement range, (the peak of the distance

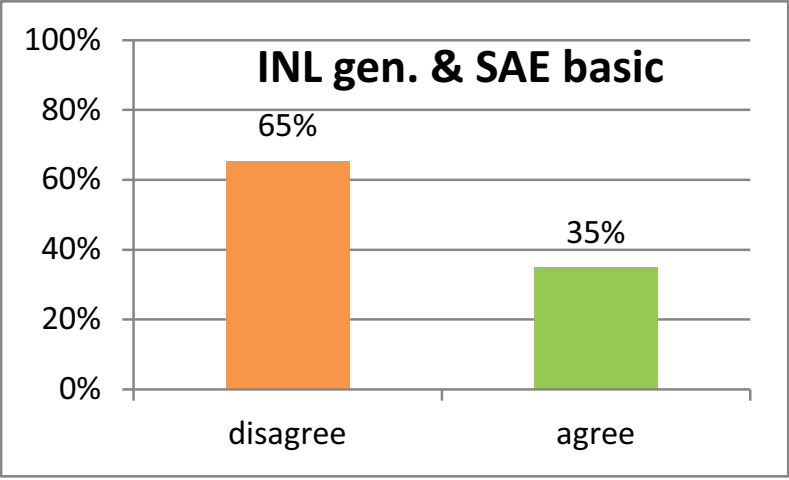

Figure 9: Distribution of agreement between INL General and SAE Basic methods based on data taken from a sample of 20,000 trips between 29 and $34 \mathrm{mph}$ average trip speed. This level of disagreement is similar to the level of disagreement between MTA and SAE Basic for the same sample of trips.

weighted MTA disagreement, see figure 10) it was found that most of these trips were classified as highway by MTA. The speed traces of these trips seemed intuitively to confirm MTA's classification.

The trips were dominated by areas of high and sustained speeds, but may have had long periods of

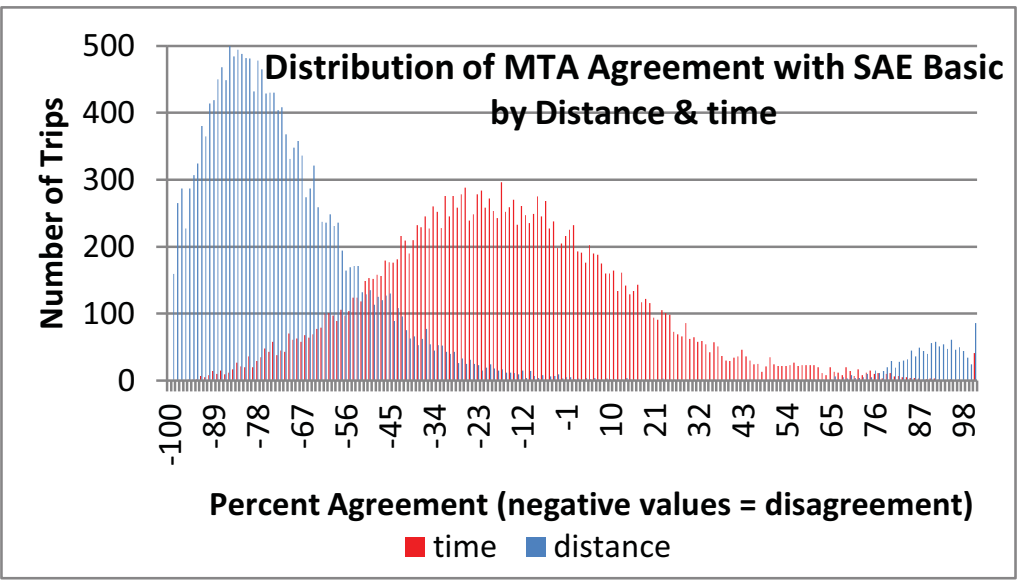

Figure 10: Distribution of agreement between MTA and SAE Basic. Dual disagreement for this sample ( 20,000 trips between 25 and $43 \mathrm{mph}$ ) is $\mathbf{7 4}$ percent and shows how much MTA tends to disagree with the SAE method. idling at the beginning, end, or between MT's.

They also sometimes were punctuated by steep decelerations. However, as agreed upon (in most cases) by both the MTA and INL General methods, these trips should still be classified as highway.
Route Types Explained BRS, 2011 


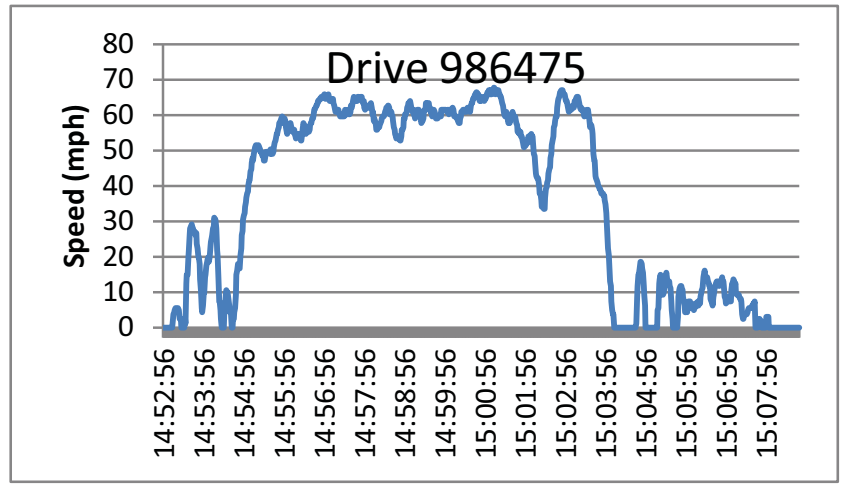

Figure 11: Speed trace of drive 986475, which INL General and SAE Basic both called a city trip, while MTA classified the trip as highway both by time and distance weighting.

\section{Mismatched Trips}

The two main route-type determination methods, the SAE Basic and INL General, have a fundamental area of disagreement concerning highway trips. J2841 specifies that any trip with average speed greater than $42 \mathrm{mph}$ is a hwy trip, while INL General specifies that any trip with average speed above $37 \mathrm{mph}$ is a highway trip. However, a trip with speeds as low as $26 \mathrm{mph}$ may be classified by INL General as highway if other conditions are met. The characteristics of trips in the region of disagreement (37 to $42 \mathrm{mph}$ ) were investigated.

Data for investigation was taken from the V2Green fleet of hybrid vehicles. Since highway trips are generally assumed to be dominated by high speeds over relatively long periods of time, the percentage

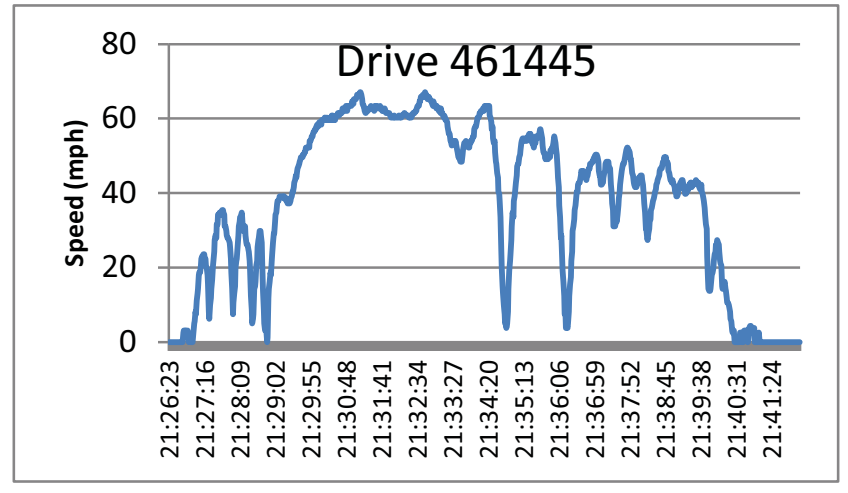

Figure 12: Drive 461445 from the V2Green database shows a speed trace typical of a trip in the 37-42 $\mathrm{mph}$ average trip speed range (classified as highway by INL General). It has around 10 percent idling time, is just less than 10 miles long, and lasted about 15 minutes. of each trip spent idling is one characteristic that was particularly interesting.

To compare percentages of time spent idling per trip; nearly 50,000 highway (INL General classification) trips from a two year period (June of 2009 to June of 2011) were considered. The trips were broken down into three categories: trips with average speeds between 26 and 37 $\mathrm{mph}$, between 37 and $42 \mathrm{mph}$, and trips with average speeds of $42 \mathrm{mph}$ and higher. While the typical $42+\mathrm{mph}$ trip idled 7 percent of trip time, a trip with average speed

There were rare cases that INL General and SAE Basic both disagreed with MTA, such as in the case of Drive 986475 as shown in figure 11. In cases such as this one, it becomes almost a decision based on personal preferences as to what route type will be assigned. However, observing the speed trace and other factors, the author still agrees with MTA.

Figure 11: The three different types of highway trips presented show how, as average speed increases, the average portion of time idling tends to decrease. Here, as average trip speed increases, the average percentage of trip time idling decreased from 15 percent (26-37 $\mathrm{mph}$ range) to 11 percent (37-42 $\mathrm{mph}$ range) to 7 percent (42+ mph range).

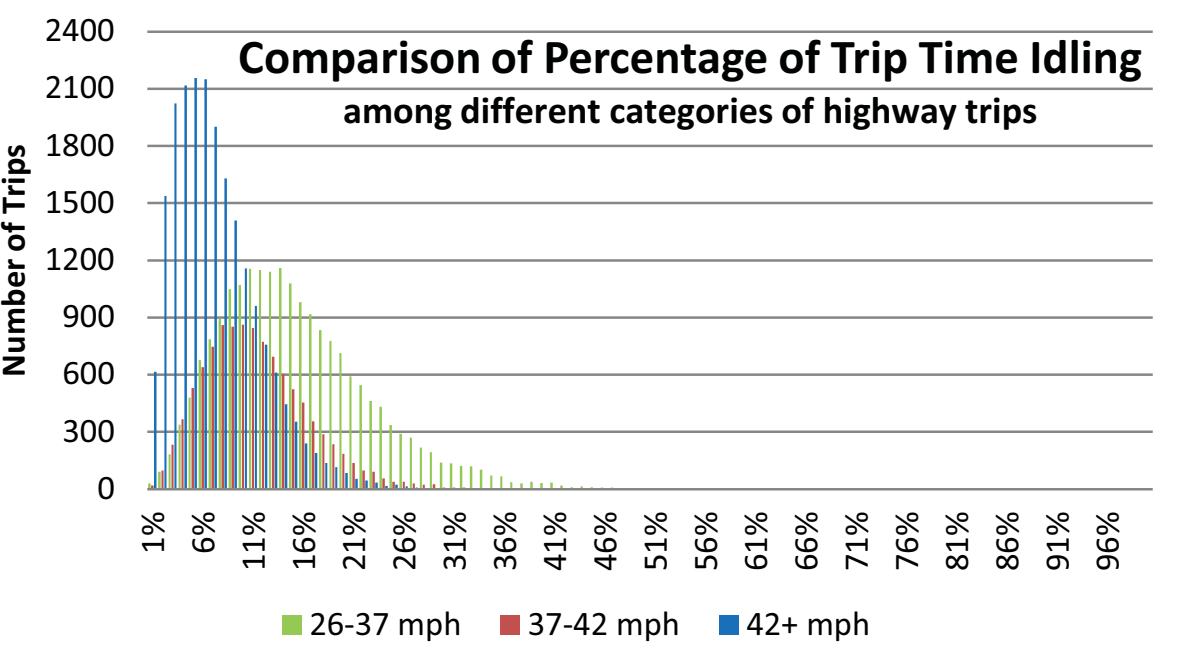


between 37 and $42 \mathrm{mph}$ spent about 11 percent of trip time idling on average, and highway trips with speeds from 26 to $37 \mathrm{mph}$ averaged an even higher (see figure 12)percentage of trip time idling.

While these differences are not drastic, they are significant and are complemented by analyzing the average distance of trips in each category. As can be seen in figure 21 (appendix), trips above $42 \mathrm{mph}$ tended to be significantly longer than average trips in the 37 to $42 \mathrm{mph}$ category or the 26 to $37 \mathrm{mph}$ category, or many trips from the broader classification of all highway trips.

\section{Minimum Trip Distance}

Among all the criteria used by the several different route type determination methods, one criterion is interestingly absent from all the methods: trip distance. Many people consider highways to be roads used to go on trips that are typically longer, perhaps from one town to another as a minimum. So, distance would seem like one natural and easily measured indicator of a highway trip. The possibility of including distance as a factor in route type determination was investigated. To consider including distance as a factor for route type determination, it was first determined what distance should be used to help divide city and highway route types.

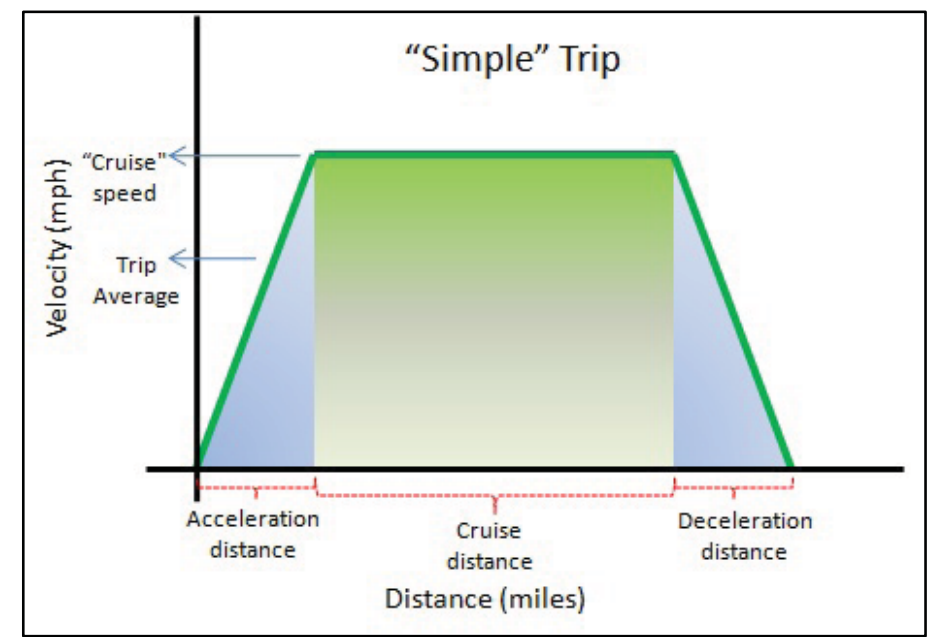

Figure 13: Illustration of a "simple" trip, beginning and ending with steady changes in velocity as well as a "cruising" section in the middle of the trip.

Some important concepts should first be defined to help determine this distance. The first concept is a "Cruise to Change in Velocity" ratio, or Cruise/ $\Delta$ Vel. ratio. This ratio compares the distance covered while at a steady speed ("cruising") to the distance covered while accelerating or decelerating. A whole number ratio indicates that at least as much distance is being covered while cruising as while speeding up or slowing down, such as would be typical during a highway trip. A fraction or decimal indicates that more speeding up and slowing down is taking place than cruising. For example, a ratio of two would mean that twice as much distance is travelled while cruising as is travelled while accelerating and decelerating, while a ratio of $1 / 4$ would mean that four times as much accelerating and decelerating occurred as cruising.

Next, to avoid overly complex situations which would muddle any attempt to reach a clear and useful standard, a simplified situation for experimentation is necessary. The "simple" trip is a trip which begins from a velocity of zero with a steady rate of acceleration until the desired cruise speed is reached. Cruise speed is then maintained until deceleration, at the inverted rate of the earlier acceleration, slows the vehicle to a stop. See figure 13. 
While this arrangement is admittedly simplistic and ignores some realities, its flaws are overshadowed by its utility. It allows the total distance of a trip, given certain other factors (listed below) to be calculated from the sum of the cruise distance and the changing velocity distance:

$$
\text { Total Distance }=\left(\frac{\left(y_{2}-y_{o a}\right) * b_{2}}{y_{o a}-y_{1}}\right)+\left(\frac{2 * y_{o a}{ }^{2}}{r}\right)
$$

where $y_{2}$ is the average velocity during acceleration and deceleration (one third of the cruise velocity), $b_{2}$ is the distance covered during either acceleration or deceleration, $y_{o a}$ is the average trip speed (oa for overall trip), $y_{1}$ is the cruise velocity, and $r$ is the rate of acceleration. Using Excel to automate unit conversion, commonly available metrics such as zero to sixty times and speed in mph can be entered to describe situations with various vehicles and different known road characteristics, such as speed-limits.

Combining the Cruise/ $\Delta$ Vel. ratio with the "Simple" trip calculator results in a powerful tool that allows for experimenting with the different variables, holding some constant while varying others, helping researchers approximate real-life situations. For example, given a certain cruising speed (say, the speed limit on a freeway), the average trip speed, and a car's zero to sixty time, items like the total distance covered during the trip as well as the seconds spent accelerating per mile during the trip and the Cruise/ $\Delta$ Vel. ratio can be calculated.

Alternately, the Cruise/ $\Delta$ Vel. ratio can be set along with the cruise speed and the zero to sixty time in order to find the minimum trip distance to meet those conditions ${ }^{8}$. Thus, by identifying the conditions that describe the "minimum" situation for a highway trip, the minimum distance for classification as a highway trip can be suggested. If a realistic minimum velocity on a common highway is $55 \mathrm{mph}$, a common zero to sixty time ${ }^{9}$ is 10 seconds, and the minimum acceptable Cruise/ $\Delta$ Vel. ratio is set at 1.5 , the minimum trip distance for highway classification becomes approximately 0.7 miles.

Setting the Cruise/ $\Delta$ Vel. ratio at 1.5 may be a debatable point. However, setting this as the minimum ratio of distance covered at cruising speed compared to distance covered by acceleration and deceleration means that a highway trip must have at least 50 percent more distance covered at cruising speeds than while changing velocity. This intuitively seems like a good minimum value for highway classification.

Common experience seems to support this idea as well. Imagine the trip described above. It could begin by turning onto a country highway from a stop and accelerating to the speed limit ( $55 \mathrm{mph}$ ), then

\footnotetext{
${ }^{8}$ Note that using Excel's “Goal Seek" function opens up even more opportunities for exploration.

${ }^{9}$ According to Edmunds (http://www.edmunds.com/tovota/prius/2009/road-test.html) the 2009 Toyota Prius has a zero to sixty time of 10 seconds. The Hymotion Prius conversions tested by INL have times closer to 12 seconds. Many sport cars may be closer to 8 seconds or even lower. Since most vehicles are, supposedly, not accelerated at the maximum possible rate consistently, 10 seconds was used as a reasonable assumption.
}

Route Types Explained BRS, 2011 
cruising for just under a half mile until decelerating until stopping. The entire trip takes 0.7 miles at an average speed of roughly $46 \mathrm{mph}$. Most people would naturally agree that travelling further (increasing the distance and the average speed) would make this trip easily classifiable as a highway trip. On the other hand, if the trip were somehow any shorter (decreasing not only distance but also average speed and the Cruise/ $\Delta$ Vel. ratio), classifying it as a highway trip would be at least doubtful.

It should be noted, however, that as the cruise speed increases linearly, the required distance for highway trip status increases exponentially. So, while at a $55 \mathrm{mph}$ cruise speed the required distance is only 0.7 miles, at $65 \mathrm{mph}$ the distance required is 1 mile, and at $80 \mathrm{mph}$, a realistic cruising speed of many freeways, the distance is about 1.5 miles. The curve is even steeper if the Cruise/ $\Delta$ Vel. ratio is increased to 2 . Once parameters such as a minimum distance of 0.7 miles are established, the usefulness of the Simple Trip and Cruise/ $\Delta$ Vel. ratio becomes clear. Standards developed using these tools can be applied to much more complex situations.

\section{Addition of New Route Type}

If a new route type determination method were to be built from the ground up, perhaps a logical and convenient place to start would be by defining a minimum trip length using the methods and tools previously explained. However, with more than three already developed methods in use, the addition of a new parameter, even one that seems as fundamental as trip distance, has to prove its necessity against the functionality of those methods already in use.

Testing was performed with two different sets of trips and the three most common route type determination methods to evaluate the usefulness of possibly adding distance as a criterion. Both sets of trips had greater than 18,000 trips. No trip was returned that was both classified as highway and was less than 0.7 miles in length for any of the methods used (INL General, MTA time/distance weighted, and SAE Basic). This suggests that the current methodologies are already effectively filtering out any trips that are too short to be considered highway trips by minimum distance standards. So, it appears that at this point, adding a criterion for minimum distance would be almost entirely redundant.

\section{Postal Route Type Re-vamp}

The possibility of adjusting the parameters used to characterize route types for the INL's USPS route type determination method was investigated. Currently, the method identifies trips as one of three different route types: stop and go, city, and highway. Stop and go trips have more than 5 stops per mile, city trips have less than 5 stops per mile and average speeds less than $37 \mathrm{mph}$, and highway trips have average speeds greater than $37 \mathrm{mph}$ and less than 5 stops per mile.

Relating these classifications and their qualifying criteria to real-life situations is important to keep the labels relevant. So, examining the types of areas and routes that postal service vehicles and workers frequently work in provides valuable perspective.

Consider first a common residential neighborhood in Idaho Falls, Idaho. A postal worker could drive from mail-box to mail-box (essentially house to house) which is called curbside delivery. This would put the 
distance between stops at about 60 feet on average in this example (according to USPS, curbside is usually 90 to $100 \mathrm{ft}$ ), or roughly 85 stops per mile. 85 stops/mi. falls close to the middle of the current stop and go stops/mi. distribution, which seems to increase the likelihood that the current methodology is correct.

However, to verify the minimum, or threshold number of stops/mi. for stop and go classification, another situation should be considered. What if instead of driving to every house, the postal worker were a bit more energy and health conscious (and maybe had a little more time to complete the route) and drove to the bottom end of one of the streets that run vertically (see figure 14), parked there, and then walked up one side of the street and down the other delivering mail to the houses, until (s)he arrived back at the vehicle, and drove to the end of the next vertical street to repeat the pattern?

In this case, which the USPS calls "park and loop delivery" the vehicle would only stop at the end of each

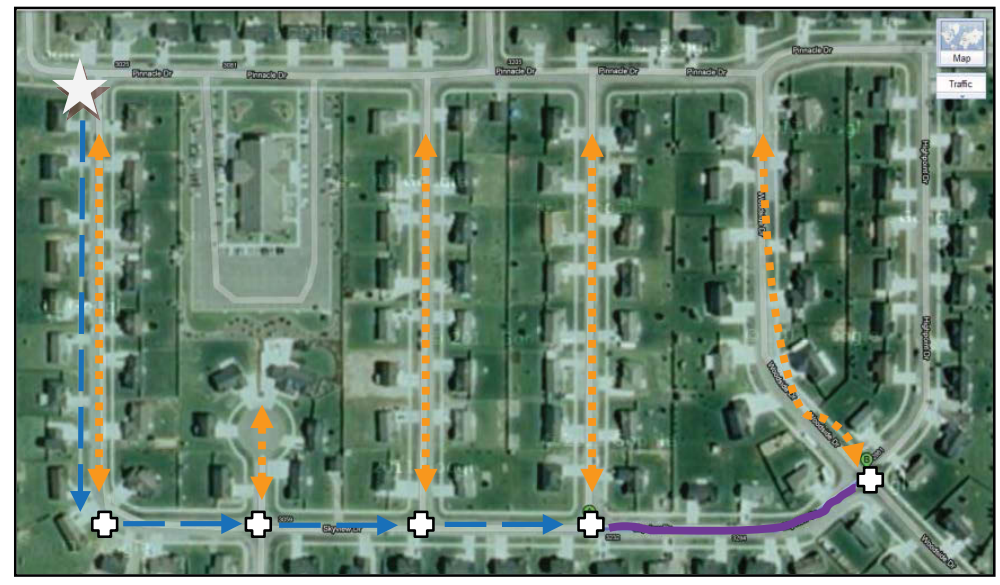

Figure 14: An example of a common residential neighborhood in which a postal worker might deliver mail to residences. This neighborhood happens to be in Idaho Falls, Idaho, near a high school (not pictured). Potential driving routes shown with blue lines (and the longest in purple), walking shown in orange. Image and distance estimates via Google Maps. street, and the distance between stops would increase to about 340 feet, or 15.5 stops/mi. on average. But, suburban streets aren't all grid-like, and toward the right hand side of the neighborhood, the road jogs, creating an extra-long drive for the postal worker (marked in purple on map). In this case the distance is 0.1 miles, or 10 stops/mi.. This seems like the longest trip that a postal vehicle could reasonably travel as part of a stop and go delivery route. This would establish a minimum stops/mi. of 10 for the stop and go classification instead of the 5 currently specified.

Further, looking at 5 stops $/ \mathrm{mi}$. through the same realistic lens means that a vehicle could travel nearly a quarter mile between deliveries. Admittedly, in many rural areas this may be a common occurrence. But, at least two reasons over-rule the idea that 5 stops/mi. remain the delivery threshold stops/mi.. First, rural areas are by far the exception in the U.S.: 80 percent of Americans live in metropolitan areas ${ }^{10}$. This means that most delivery areas will be at least as densely concentrated as the area in the example.

The second reason is based on the utility of descriptive characterizations such as "stop and go" or "city" or "highway". If the descriptions are to have any real meaning, they must each describe a significant number of (or otherwise meaningful) portion of the population. If a large enough portion of the population being described falls under only one description, that description begins to be less and less useful in distinguishing one trip from another.

\footnotetext{
${ }^{10}$ http://www.time.com/time/covers/20061030/where we live/, http://www.fhwa.dot.gov/planning/census issues/metropolitan_planning/cps2k.cfm
} 


\section{USPS Route Type Distribution}

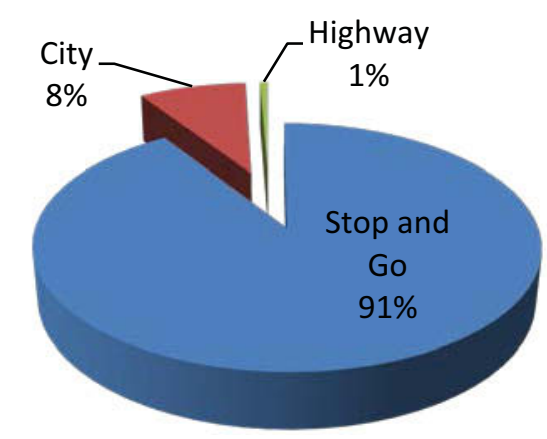

Figure 15: Distribution of route type classifications under current INL USPS definitions.
This is, to an extent, the current situation with the USPS route types. Over 90 percent of all USPS trips are currently classified as stop and go trips (see figure 15). Of course, attempts should not be made to redefine reality to more neatly fit pre-conceived notions, but a situation like this should encourage the consideration of adjusting the descriptions used to provide a higher resolution view of the circumstances.

Providing a clearer view of the USPS route types can be accomplished by adjusting the required stops/mi.

for Stop and Go route type up to 10 stops/mi., as previously discussed. Since most of the trips abandoned by this category would be absorbed by the city category, another suggestion would be to rename the city category (to avoid confusion with "city" classifications in other common route type determination methodologies) to something like, "transit" or "commute." Such a name would hopefully communicate that this type of trip is likely used to travel from one neighborhood to another or from the Post Office to a delivery area.

The highway category, although by far the smallest portion of trips, should remain unchanged since it is very indicative of the reality of Postal Service vehicle use and provides useful perspective on the entire situation. If these changes were adopted, the distribution of route type classifications would appear as shown in figure 16.

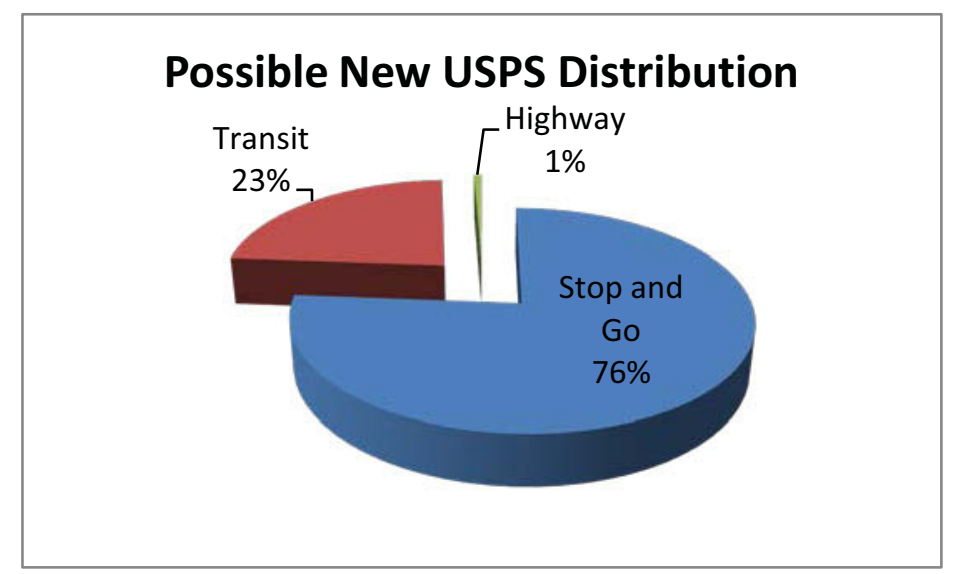

Figure 16: Distribution of trip types according to suggested new types and definitions of route types.

\section{Summary}

Several methods for classifying the route type of a trip were examined. The development of a new route type determination methodology, MicroTrip Analysis, was also described, and in-depth comparisons were made between the results of MTA and various other methods. Adjustment of the INL General route type determination method was considered but not shown to be needed. The possibility of including distance as a factor in route type determination was evaluated and found to be unnecessary. INL's USPS route type determination method and classifications were evaluated and suggestions were made to improve the clarity and utility of the method. 


\section{Appendix}

Table 3: Shows agreement statistics (by number of trips) for "X" fit method (SAE) and INL General method. Analysis was made on a sample of more than 4,500 trips from the Green IT Alliance vehicle.

\begin{tabular}{|lcc|}
\multicolumn{2}{c}{ "X" fit Method Agreement with INL General Method } \\
\hline Agreement & \# of trips Mismatched & Percent Agreement \\
\hline Pure City & 29 & 99 \\
\hline Weighted City & 1025 & 10 \\
\hline Weighted Hwy & 0 & 100 \\
\hline Pure Hwy & 0 & 100 \\
\hline Total & 1054 & 77 \\
\hline
\end{tabular}

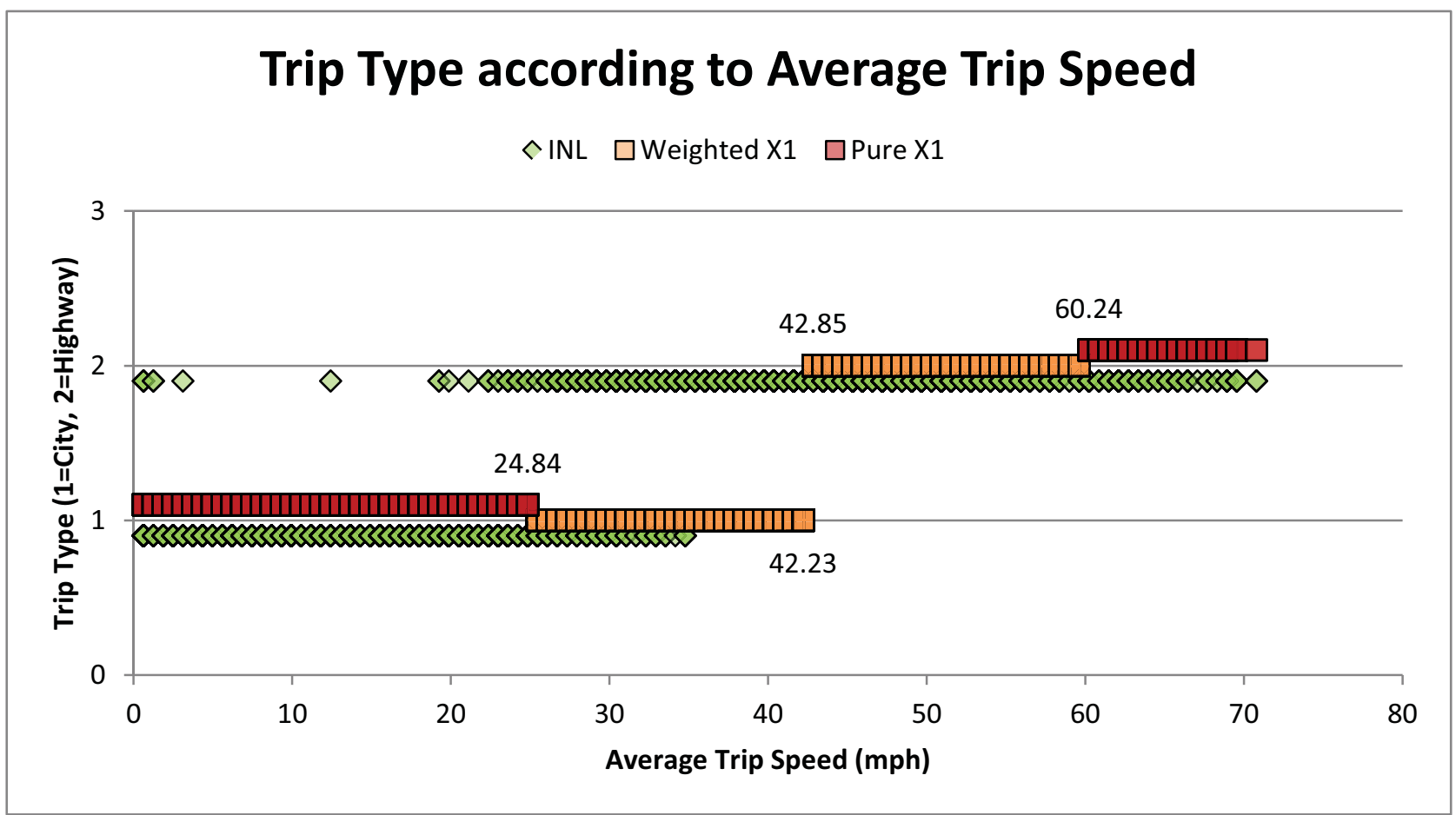

Figure 17: Agreement between " $X$ " fit method (SAE) and INL General method showing abrupt change from " $X$ " fit city to highway and region of intense disagreement between the two methods between the speeds of 25 and $42 \mathrm{mph}$. Data came from more than 4,500 trips from the Green IT Alliance vehicle. Note: This data also helped to identify an error in an early stage of use of the INL General method; the trips classified by INL General as highway that have average trip speeds below 26 mph were classified erroneously. The error in classification methodology has since been corrected. 
INL/EXT-11-23204

\section{"X" fit Vehicle Miles Travelled Detailed}

100\% Highway miles travelled

100\% City miles travelled

Mixed Region Highway

Mixed Region City

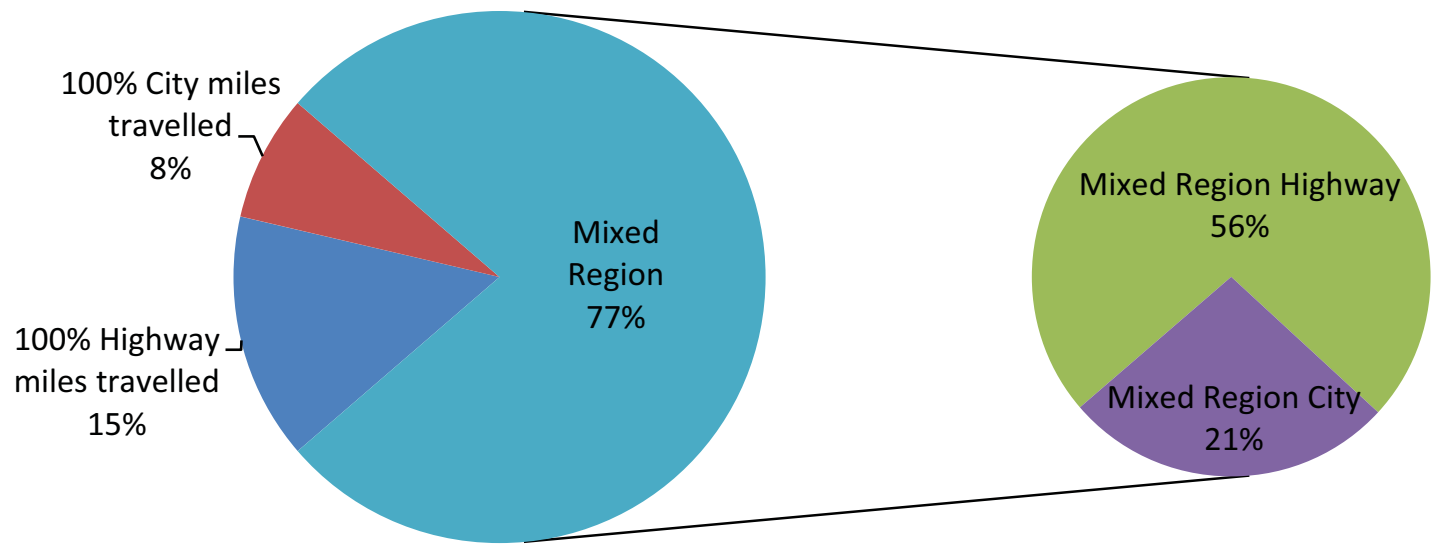

Figure 18: Breakdown of "X" fit route types by vehicle miles travelled (VMT). Notably, only 33 percent of VMT could be immediately identified as either definitely highway or definitely city. The remaining 77 percent of VMT had at least some level of uncertainty as to route type. Data from Green IT Alliance vehicle.

\section{INL Method \# of Trips}

\section{"X" fit \# of Trips}
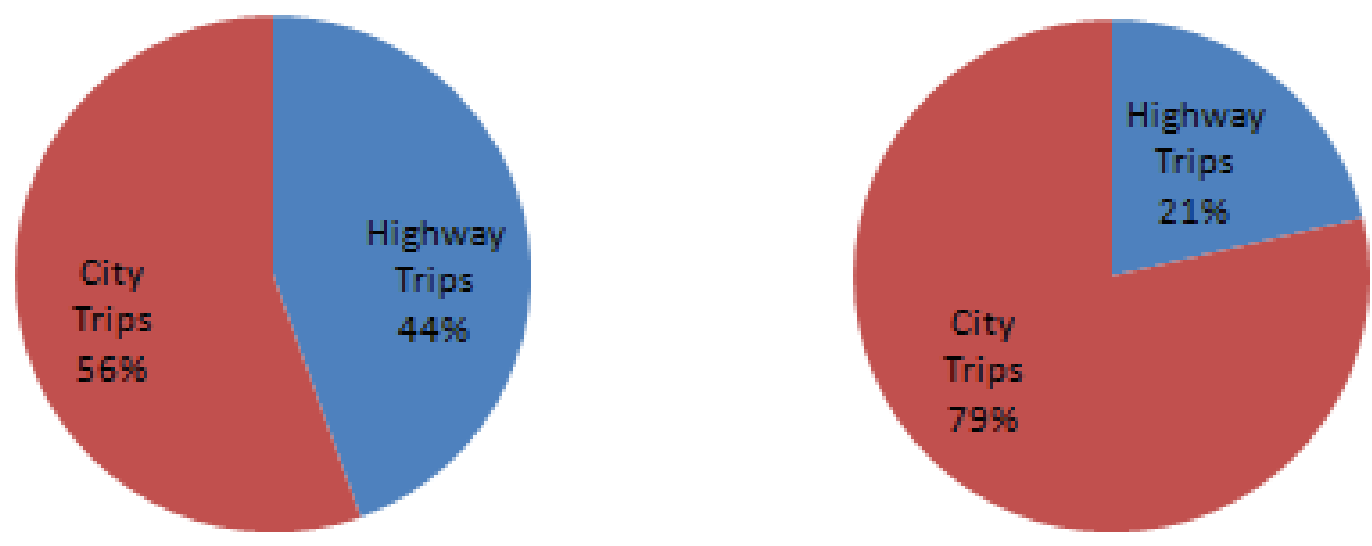

Figure 19: Difference in proportions of city and highway trips according to determination method. The INL General method classifies 56 percent of the Green IT Alliance vehicle's trips as city trips while the " $X$ " fit method classifies 23 percent more of the same vehicle's trips as city. Comparing these charts to the previous figure also serves as an example of how VMT and number of trips are completely different metrics. Compare the ratios of city to highway based on number of trips to the ratios of city to highway based on VMT; there are many more miles travelled in "highway" mode than in "city" mode even though there are more city trips than highway trips. 


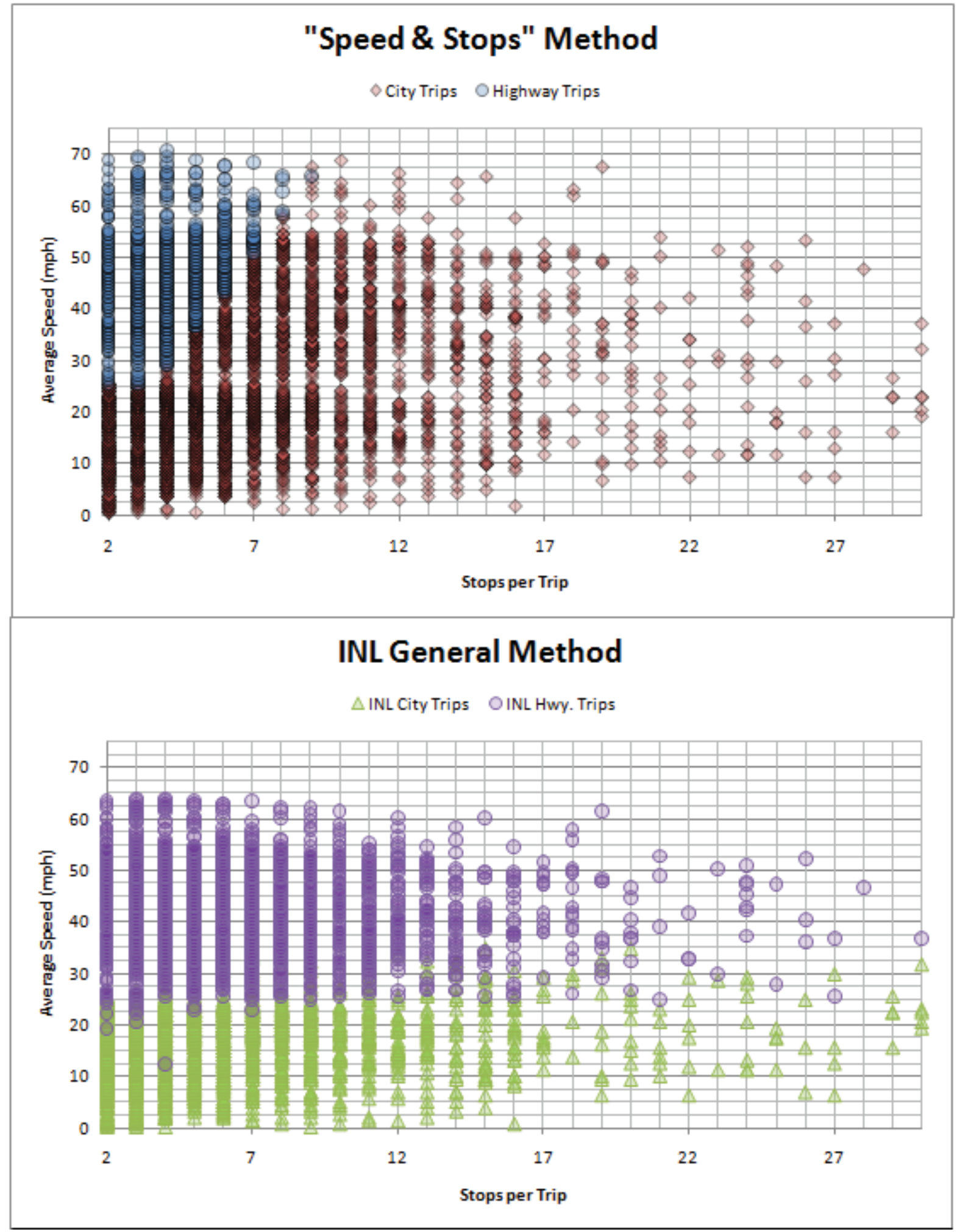

Figure 20: "Speed \& Stops" method compared to INL General method using parameters of average trip speed and stops per trip. As can be seen, the INL General method classifies fewer trips as city than the Speed \& Stops method. It classifies trips based on a 55 percent city $\mathbf{4 5}$ percent highway VMT split and does so using a specified ratio of average trip speed to stops per trip as well as a minimum speed (25 mph) for highway. Speed \& Stops is the most complex of the SAE J2841 methods. As 
in the " $X$ " fit method comparison, note how INL overlaps the area where some trips are classified while the SAE method maintains a more rigid split between the classifications.

Table 4: Description of trips and Vehicle Miles Travelled (VMT) for the USPS fleet of electric delivery vehicles from a sample of more than 3,000 trips. As can be seen, highway trips account for a very small percentage of trips and VMT.

\begin{tabular}{|lcccc|} 
trip types & U of trips & $\begin{array}{c}\text { USPS Route Types } \\
\text { percent of trips }\end{array}$ & VMT & percent of VMT \\
\hline Highway & 3 & 0.06 & 78.05 & 4 \\
\hline City & 252 & 5.45 & 756.64 & 41 \\
\hline Stop and Go & 3015 & 65.25 & 1032.02 & 55 \\
\hline
\end{tabular}

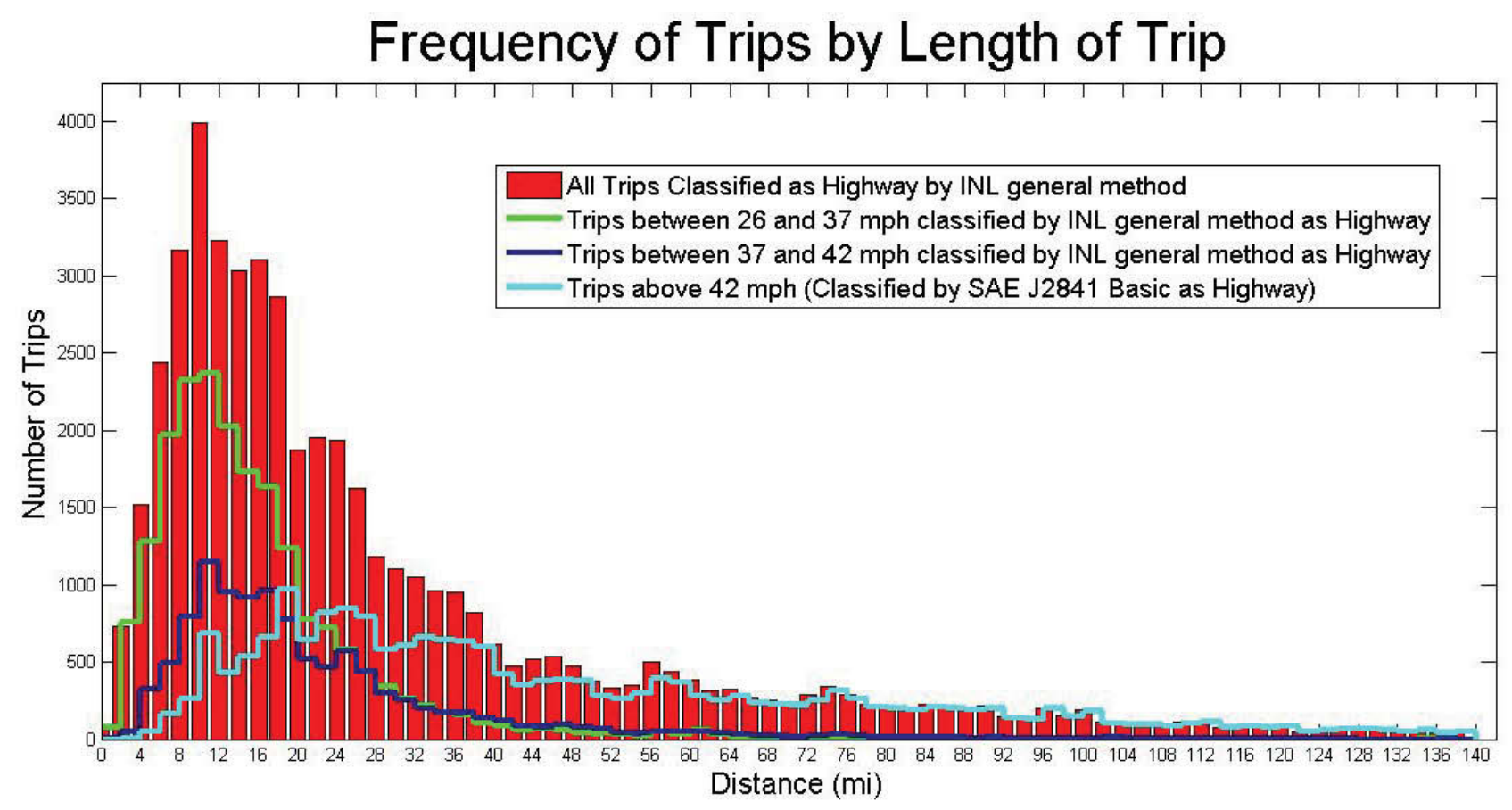

Figure 21: Histogram resulting from the analysis of nearly 50,000 trips classified as highway by the INL General method (red bars) from a two year period of INL testing of plug-in hybrid vehicles. Note that for average trip speeds between 26 and $37 \mathrm{mph}$, INL General may, depending on other factors, classify a trip as highway. Above $37 \mathrm{mph}$ INL General automatically classifies trips as highway, and above $42 \mathrm{mph}$ INL General and SAE Basic both automatically call the trip highway. This last case is illustrated by the area enclose by the light blue line. These trips tend to be over longer distances and at higher speeds. However, a large portion of trips classified by the INL General method as highway take place at much lower speeds and shorter distances.

Another interesting observation is that the great majority of highway trips over about $\mathbf{4 0}$ miles long are taken at average speeds above $42 \mathrm{mph}$. Trips with distances less than that are much more varied in their average speed category. 
INL/EXT-11-23204
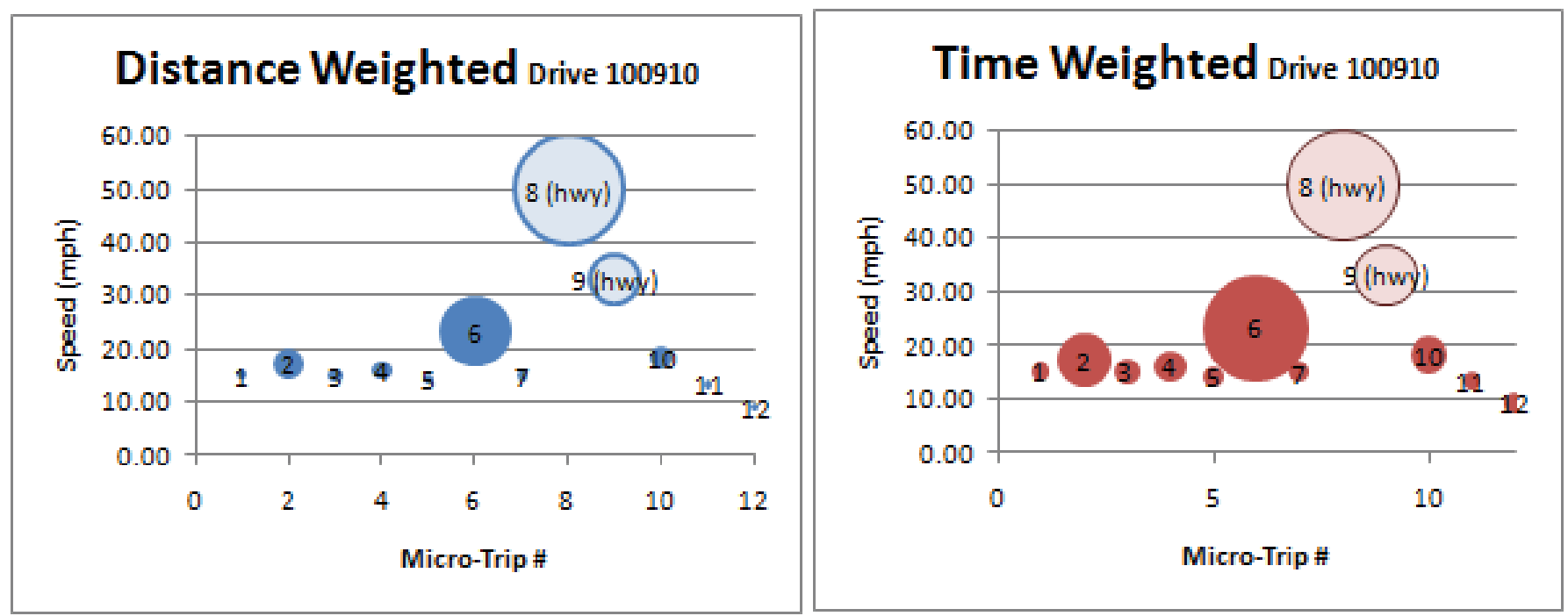

Figure 22: To calculate the percentage of each trip that was highway-like and city-like, each micro-trip was weighted, both according to distance (left) and according to time (right). Here, each circle represents the micro-trip of the same number. A larger circle means more distance or time was covered by that micro-trip and is thus weighted more heavily. Note how the circles correspond neatly with the speed trace in figure 18. MT's that were classified as highway are shown in lighter colors.

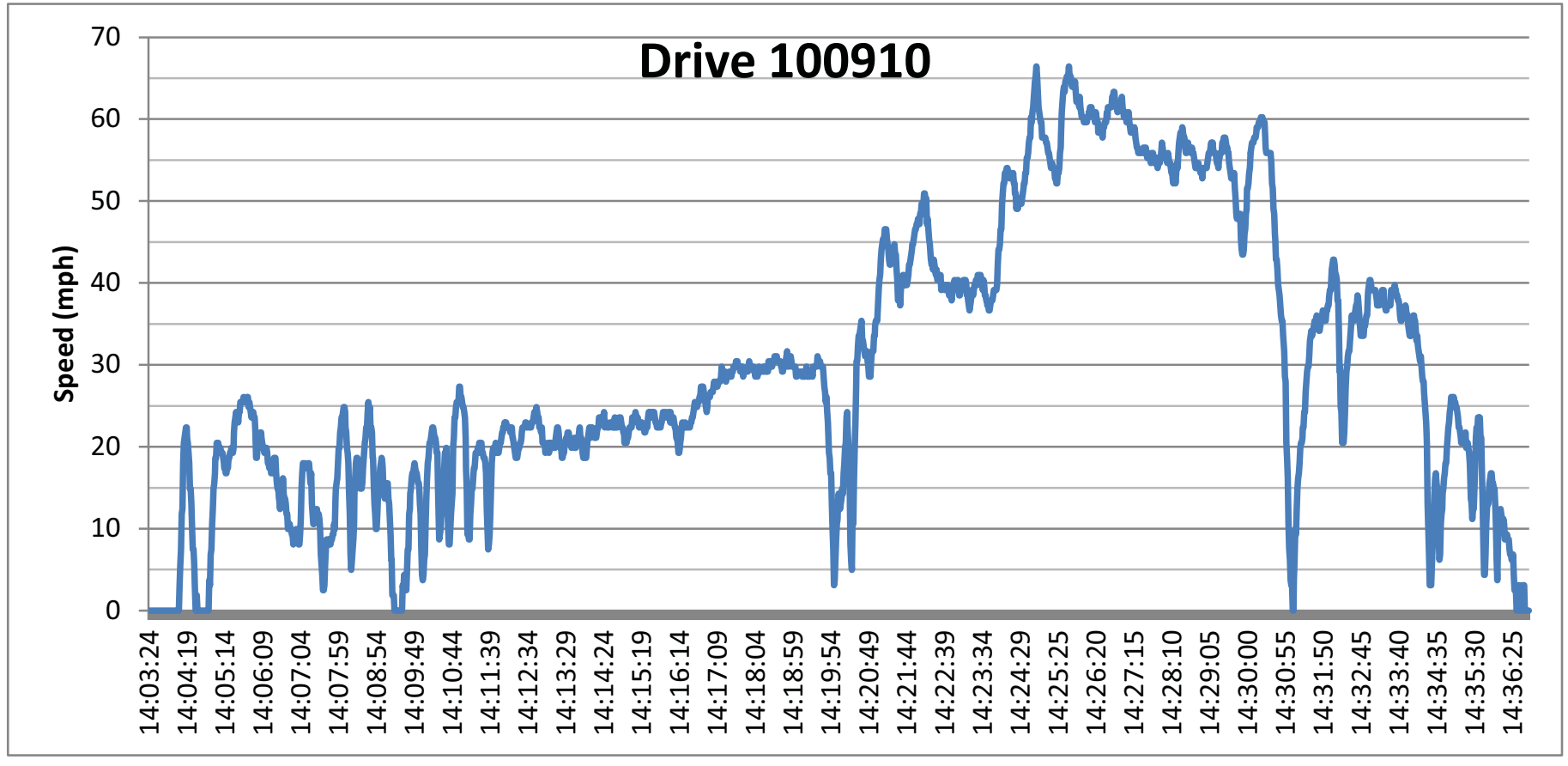

Figure 23: Speed trace of Drive 100910 here shows the relatively large number of micro-trips in this trip. The largest micro-trip, (from about 14:20 to 14:30) corresponds to number eight in the figures below. The speed threshold to begin or end a micro-trip is $5 \mathrm{mph}$. 
INU/FXT-11-23204

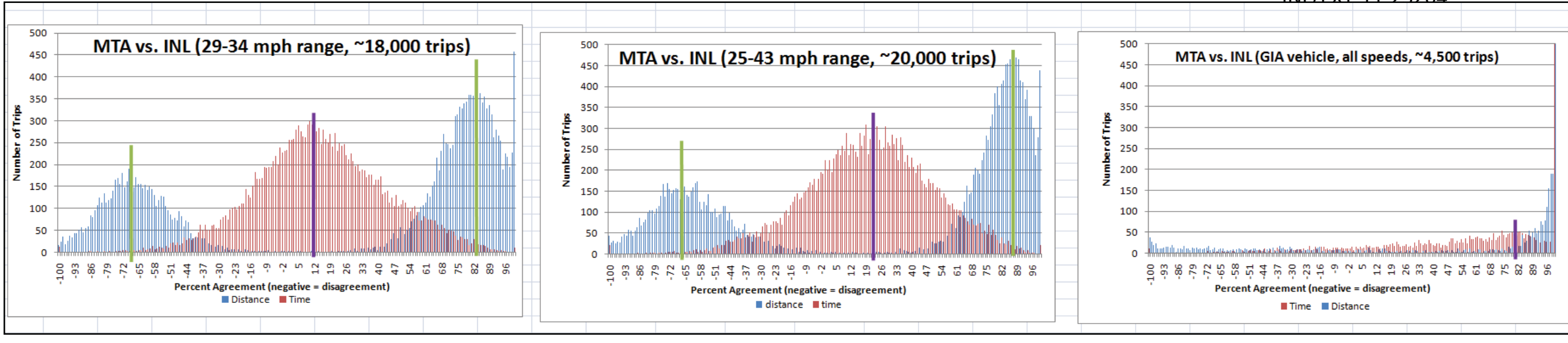

Figure 24: Displays histograms of distribution of agreement for three samples from the V2 Green database, progressing from a narrow range of average trip speeds on the left (all trips between 29 and $34 \mathrm{mph}$ ), to a more inclusive sample in the middle (25 to $43 \mathrm{mph}$ ), and an all speeds included sample from one vehicle (the Green IT Alliance vehicle) on the right. The vertical green bars mark the approximate peaks of the bi-modal distance weighted MTA agreement, and the purple bars mark the approximate peaks of the time weighted MTA agreement. Note how as the sample width increases, the percent agreement for both time and distance weighted MTA methods tend to increase. In the sample on the right, the distance weighting has no clear "peak" since over 1,000 of its trips agree $100 \%$ (graph scale adjusted for viewing).

Table 5: Shows data from each of the three samples concerning agreement between MTA and INL General.

\begin{tabular}{|lcccc|}
\hline Sample & $\begin{array}{c}\text { Dual } \\
\text { Disagreement }\end{array}$ & $\begin{array}{c}\text { Dual } \\
\text { Agreement }\end{array}$ & $\begin{array}{c}\text { Partial } \\
\text { Agreement }\end{array}$ & $\begin{array}{c}\text { At Least Partial } \\
\text { Agreement }\end{array}$ \\
\hline 29-34 $\mathbf{~ m p h}$ & $24 \%$ & $58 \%$ & $18 \%$ & $76 \%$ \\
\hline 25-43 $\mathbf{~ m p h}$ & $19 \%$ & $60 \%$ & $21 \%$ & $81 \%$ \\
\hline GIA vehicle & $12 \%$ & $76 \%$ & $11 \%$ & $87 \%$ \\
\hline
\end{tabular}

